\title{
Transition Probabilities of Forbidden Lines
}

\author{
R. H. Garstang ${ }^{1}$
}

(October 2, 1963)

\begin{abstract}
This paper describes calculations of the transition probabilities of forbidden lines (magnetic dipole and electric quadrupole radiation) of laboratory and astrophysical interest. Results are given for Ti iII, Cr II, Cr Iv, Mn v, Mn vi, Fe vi, Fe viI, Ni I, Cu II, Ga I, Ge I,

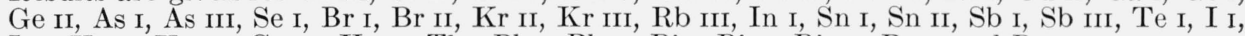

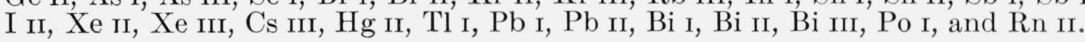

\section{Introduction}

This paper presents the results of calculations of the transition probabilities of forbidden lines for a number of atoms and ions of astrophysical or laboratory interest. Much work has been done in the past on atoms in the first two short periods and their isoelectronic sequences, and selected ions in the iron group have also been studied. A few additional ions in the iron group need study, chiefly with a view to astrophysical applications. These form the subject of sections 2 through 4 of the present paper. There have been few calculations on forbidden lines of heavier elements. Only a few are of possible astrophysical interest; a number have been observed in the laboratory. Calculations of their transition probabilities are not difficult, and have been carried out for many atoms and ions, the results being given in section 5 of this paper. They include, it is thought, every case in which one or more forbidden lines in an atom has been observed in laboratory sources, and for which transition probabilities have not previously been computed.

A comprehensive survey of this subject has recently been given [1], ${ }^{2}$ and in this paper we shall only give such details as are immediately relevant to the individual atoms being considered. Unless otherwisa mentioned all observed atomic energy levels have been taken from [2]. The procedure, now well established, is to take the quantum mechanical energy matrices including spin-orbit interaction (and, where necessary, configuration interaction) and determine the parameters (radial integrals) in these matrices so that the eigenvalues of the matrices reproduce the observed energies as accurately as possible. The eigenvectors provide the transformation from $L S$-coupling to intermediate coupling. The matrices of the square roots of line strengths are set up, the transiormation to intermediate coupling

\footnotetext{
1 Normally at University of London Observatory, Mill Hill Park, London, N.W. 7, England, where part of this work was performed. The remainder was performed while the author was at the Atomic Physics Division, National Bureau of Standards, during 1961 and 1962, and is a part of project DEF ENDER, sponsored by the Advanced Research Projects Agency, Department of Defense, through the Office of Naval Research.

2 Figures in brackets indicate the literature references on page 71
}

carried out, and the final line strengths converted to transition probabilities. The total transition probability for a line is the sum of the magnetic dipole transition probability $\left(A_{m}\right)$ and the electric quadrupole transition probability $\left(A_{q}\right)$.

\section{Lines of TiIII, MnVI, FeVII, CrIV, MnV, and $\mathrm{FeVI}$}

In Ti III, Mn vi, and Fe vir the transitions take place within the $3 d^{2}$ configuration. Fe viI was studied by Pasternack [3]; the other two ions do not appear to have been the subject of earlier forbidden line calculations. The spin-orbit matrix was taken from Condon and Shortley [4, p. 269]; the electrostatic energies were treated as arbitrary parameters. The parameters obtained by fitting the theory to the observed energies are given in table $1 ; \mathrm{E}\left({ }^{1} \mathrm{~S}\right)$ was estimated using the theoretical formulas for electrostatic energies [5] including an $\alpha L(L+1)$ correction [6]. The resulting calculated energies are given in table 2. The only significant comparison with observation is for the ${ }^{3} \mathrm{~F}$ and ${ }^{3} \mathrm{P}$ term intervals, for which the agreement is quite good, showing that the intermediate coupling theory provides a fair representation of the atomic fine structure. The line strength matrix for magnetic dipole radiation was obtained from formulae of Shortley [7], the electric quadrupole line strength matrix from Pasternack [3]

TABLE 1. Parameters for the $3 \mathrm{~d}^{2}$ configurations in $\mathrm{Ti}$ III and Mn v I

(Units: $s_{q}$ in atomic units, others in $\mathrm{cm}^{-1}$ )

\begin{tabular}{c|r|r}
\hline \hline Parameter & Ti III & Mn vI \\
\cline { 2 - 3 } & & \\
\cline { 2 - 3 } $\mathrm{E}\left({ }^{3} \mathrm{~F}\right)$ & 243 & 974 \\
$\mathrm{E}\left({ }^{1} \mathrm{D}\right)$ & 8482 & 15446 \\
$\mathrm{E}\left({ }^{3} \mathrm{P}\right)$ & 10657 & 18274 \\
$\mathrm{E}\left({ }^{1} \mathrm{G}\right)$ & 14398 & 25502 \\
$\mathrm{E}\left({ }^{1} \mathrm{~S}\right)$ & $(32881)$ & $(57600)$ \\
$\zeta$ & 118 & 465 \\
$s_{q}$ & 2.45 & 0.979 \\
\hline
\end{tabular}


TABLE 2. Energy levels in the $3 \mathrm{~d}^{2}$ configurations in Ti III and $\mathrm{Mn}$ vi

(Units: $\mathrm{cm}^{-1}$ )

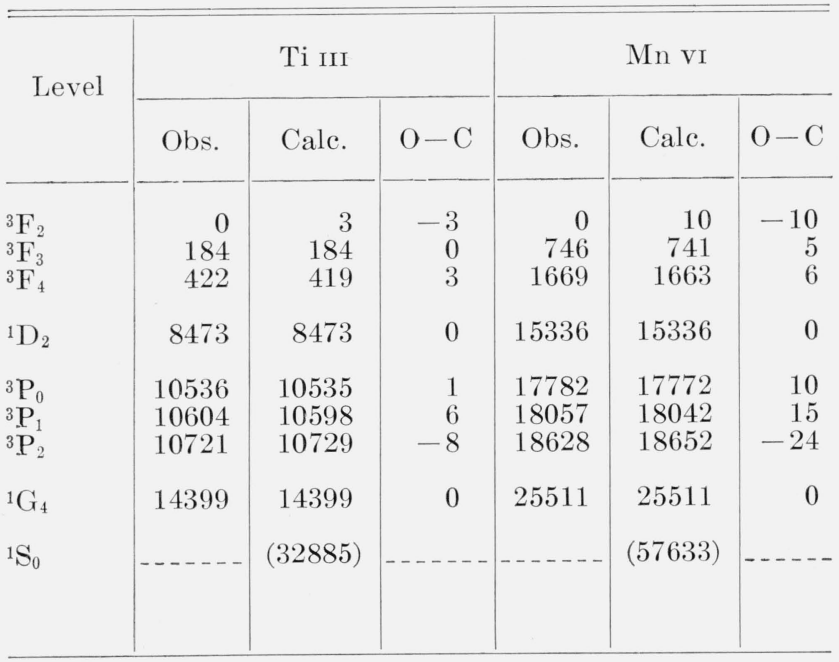

TABLE 3. Transition probabilities of [Ti $\mathrm{III}]$ and $[\mathrm{Mn} \mathrm{VI}]$ (Units: $\sec ^{-1}$ )

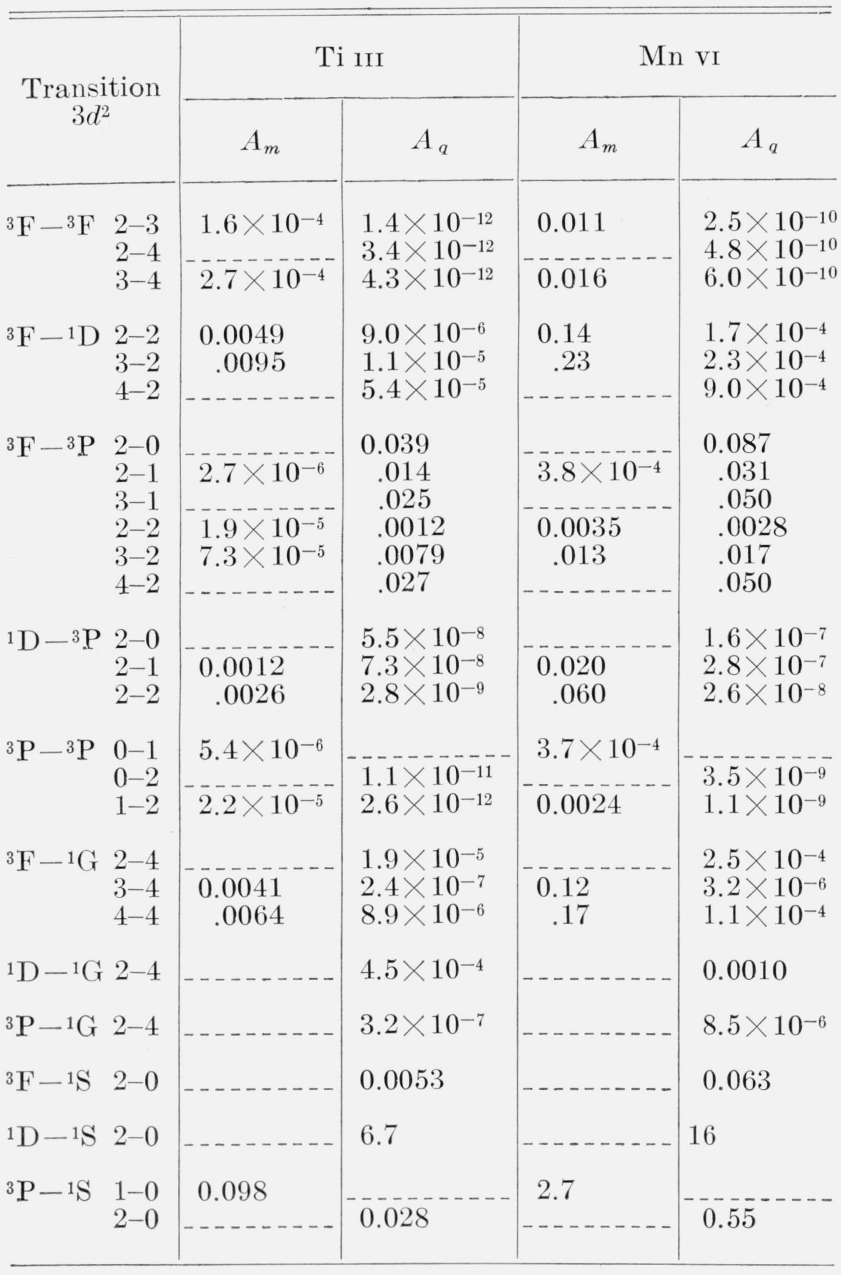

with corrections by Garstang [8], and the radial in tegrals

$$
s_{q}=\int_{0}^{\infty} r^{2} \mathrm{P}^{2}(3 d) d r
$$

were obtained from wave functions given by Watson [9]. The values of $s_{q}$ used are listed in table 1 . The intermediate coupling transformations and the final transition probabilities were computed in the usual way. The results are listed in table $3 . A_{m}$ and $A_{q}$ denote spontaneous emission transition probabilities in $\mathrm{sec}^{-1}$; the total transition probability is $A_{m}+A_{q}$.

The results obtained for Mn vi may be compared with those obtained by Pasternack for Fe viI. The results show the usual trend of increasing transition probabilities along the isoelectronic sequence. Pasternack used $s_{q}=1.52$ for Fe viI, based on a rather crude estimate of certain screening constants. A better estimate of $s_{q}$ can now be obtained from Watson's wave functions, based on an extrapolation of $s_{q}^{-1 / 2}$ along the isoelectronic sequence, Mn vi being the highest ion of this sequence for which wave functions were computed. The resulting estimate of $s_{q}$ is given in table 4 . The magnetic dipole transition probabilities obtained by Pasternack are unchanged on a change of $s_{q}$. The electric quadrupole strengths must be multiplied by the square of the ratio of the new $s_{q}$ to the old $s_{q}$. The electric quadrupole transition probabilities must be multiplied by this same correction factor, which is given in table 4. Pasternack also performed calculations on Cr Iv, Mnv, and Fe vi, for which the transitions take place within the $3 d^{3}$ configuration. We have computed improved values of $s_{q}$ for these three ions from the wave functions published by Watson. The values of $s_{q}$ are given in table 4 together with correcting factors by which Pasternack's electric quadrupole transition probabilities are to be multiplied to take account of the revised $s_{q}$. As for Fe viI, the magnetic dipole transition probabilities are unaffected by the change in $s_{q}$.

Bowen [10] observed the transitions ${ }^{3} \mathrm{~F}_{2}-{ }^{1} \mathrm{D}_{2}$ ( $\lambda 6518.3),{ }^{3} \mathrm{~F}_{4}-{ }^{3} \mathrm{P}_{2}(\lambda 5894.0)$, and ${ }^{3} \mathrm{~F}_{3}-{ }^{3} \mathrm{P}_{1}(\lambda 5776.4)$ of Mn vi in a planetary nebula. No forbidden lines of 'Ti III appear to have been observed.

TABLE 4. Radial integrals and correction factors to be applied to certain transition probabilities

\begin{tabular}{l|c|c}
\multicolumn{2}{c}{ (Units: $s_{q}$ in atomic units) } \\
\hline \hline \multicolumn{1}{c|}{ Ion } & $s_{q}$ & $\begin{array}{c}\text { Correction } \\
\text { factor }^{\mathrm{a}}\end{array}$ \\
\hline Fe vII & & \\
Cr IV & 0.84 & 0.30 \\
Mn v & 1.45 & .144 \\
Fe vI & 1.10 & .185 \\
& .89 & .24
\end{tabular}

a To be applied to electric quadrupole transition probabilities published by Pasternack [3].

b New wave junctions computed by S. J. Czyzak of WrightPatterson Air Force Baselindicate $5_{q}=\mathbf{0 . 8 0}$ for Fe vir, leading to a correction factor 0.28 . 


\section{Lines of $\mathrm{Cr}$ II}

A complete study of the forbidden lines of $\mathrm{Cr}$ II would necessitate a very long investigation which the astronomical importance of this ion is hardly sufficient to justify. It so happens that the one multiplet of most importance can be simply treated. This is the transition $3 d^{5}{ }^{6} \mathrm{~S}-3 d^{4} 4 s{ }^{6} \mathrm{D}$. The four strongest lines of this multiplet were observed by Thackeray [11] in the infrared spectrum of $\eta$ Carinae. ${ }^{6} \mathrm{~S}$ and ${ }^{6} \mathrm{D}$ are the only sextet terms in their respective configurations, and consequently there are no large off-diagonal matrix elements connecting them with other terms. Experience (especially with Fe II [12]) has shown that in these circumstances, for a transition allowed in LS-coupling, magnetic dipole radiation is likely to be negligible and the $L S$-coupling approximation will give excellent values for the electric quadrupole transition probabilities. The total multiplet strength is given in the appendix to the present paper. The individual line strengths were obtained, and converted to transition probabilities. The radial integral

$$
s_{q}=\int_{0}^{\infty} r^{2} \mathrm{P}(3 d) \mathrm{P}(4 s) d r
$$

was estimated by extrapolating $s_{q}^{-1 / 2}$ from the values previously obtained for Fe II [12] and Ni II [13]. We adopted $s_{q}=-3.5$. The results are listed in table 5.

TABLE 5. Electric quadrupole transition probabilities for Cr II $3 \mathrm{~d}^{5}{ }^{6} \mathrm{~S}-3 \mathrm{~d}^{4} 4 \mathrm{~s}^{6} \mathrm{D}$

\begin{tabular}{c|r}
\hline \multicolumn{2}{|c}{$\left(\right.$ Units: $\left.^{-1}\right)$} \\
\hline Line & \multicolumn{1}{c}{$A_{q}$} \\
\hline${ }^{6} \mathrm{~S}_{21 / 2}-{ }^{6} \mathrm{D}_{1 / 2}$ & 0.067 \\
$-{ }^{6} \mathrm{D}_{11 / 2}$ & .069 \\
$-{ }^{6} \mathrm{D}_{21 / 2}$ & .072 \\
$-{ }^{6} \mathrm{D}_{31 / 2}$ & .077 \\
$-{ }^{6} \mathrm{D}_{41 / 2}$ & .083 \\
\hline
\end{tabular}

\section{Lines of $\mathrm{Ni} \mathrm{I}$ and $\mathrm{Cu}$ II}

In connection with some intensity calculations on permitted transitions the writer undertook a study of $\mathrm{Ni} \mathrm{I}$, and part of that work may also be used in calculations on forbidden lines. The lower levels of $\mathrm{Ni}$ I arise from the configurations $3 d^{10}, 3 d^{9} 4 s$, and $3 d^{8} 4 s^{2}$. The energy levels have been fitted to the theory and parameters estimated in the usual way. The formulae for the electrostatic energies were obtained from [4, p. 299] and [5, eq (78)], an $\alpha L(L+1)$ correction [6] being added for the $3 d^{8} 4 s^{2}$ configuration. The configuration interaction matrix elements were obtained from [14, eqs (75) and (81)]. The spin-orbit interaction matrix elements were taken from $\left[4\right.$, p. 269] with changes in the sign of $\zeta$ (for $d^{8}$ or $d^{9}$ instead of $d^{2}$ or $d$ ), and of the phase of $d s$ (instead of $s d$ ). The adopted parameters are given in table 6. The configuration interaction parameter $\mathrm{H}_{2}$ was neglected; a study by Racah and Shadmi [15] showed that $\mathrm{H}_{2}$ is very small for Ni II, and presumably also for $\mathrm{Ni}$. Table 7 gives the observed energies and those calculated from the parameters in table 6 . The Landé $g$-factors are also given. The overall agreement of observation and calculation is very satisfactory. The line strength matrices were obtained in the usual way $[3,7,8,16]$ and intermediate coupling transformations carried out to obtain the final line strengths and transition probabilities. The only problem which arose was the adoption of numerical values of the radial integrals

TAвLE 6. Adopted parameters in Ni I

(Units: $S_{q}$ in atomic units, others in $\mathrm{cm}^{-1}$ )

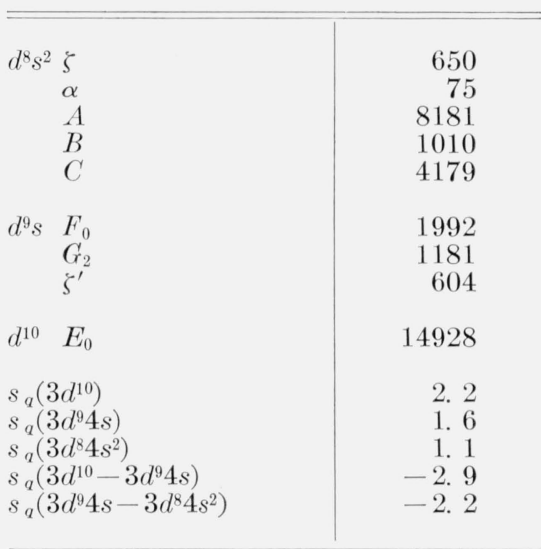

TABLE 7. Observed and calculated energy levels and Landé g-factors

\begin{tabular}{|c|c|c|c|c|c|c|}
\hline \multirow[b]{2}{*}{ Term } & \multirow[b]{2}{*}{$J$} & \multicolumn{2}{|c|}{ Energy levels } & \multicolumn{3}{|c|}{ Landé $g$-factors } \\
\hline & & Observed & $\begin{array}{l}\text { Calcu- } \\
\text { lated }\end{array}$ & $\begin{array}{c}\text { Ob- } \\
\text { served }\end{array}$ & $\begin{array}{l}\text { LS- } \\
\text { cou- } \\
\text { pling }\end{array}$ & $\begin{array}{l}\text { Calcu- } \\
\text { lated }\end{array}$ \\
\hline $3 d^{8} 4 s^{2} a^{3} \mathrm{~F}$ & $\begin{array}{l}4 \\
3 \\
2\end{array}$ & $\begin{array}{c}\mathrm{cm}^{-1} \\
0^{-1332} \\
1332^{-133} \\
2217^{-885}\end{array}$ & $\begin{array}{c}\mathrm{cm}^{-1} \\
7^{-1319} \\
1326^{-131} \\
2214^{-888}\end{array}$ & $\begin{array}{l}\text { 1. } 250 \\
\text { 1. } 083 \\
0.671\end{array}$ & $\begin{array}{l}\text { 1. } 250 \\
\text { 1. } 083 \\
0.667\end{array}$ & $\begin{array}{l}\text { 1. } 250 \\
\text { 1. } 083 \\
0.670\end{array}$ \\
\hline $3 d^{9} 4 s \quad a^{3} \mathrm{D}$ & $\begin{array}{l}3 \\
2 \\
1\end{array}$ & $\begin{array}{c}205 \\
880^{-675} \\
1713^{-833}\end{array}$ & $\begin{array}{r}207 \\
875^{-668} \\
1717^{-842}\end{array}$ & $\begin{array}{l}\text { 1. } 332 \\
\text { 1. } 149 \\
\text { 0. } 497\end{array}$ & $\begin{array}{l}1.333 \\
1.167 \\
0.500\end{array}$ & $\begin{array}{l}\text { 1. } 333 \\
1.151 \\
0.500\end{array}$ \\
\hline $3 d^{9} 4 s a^{1} \mathrm{D}$ & 2 & 3410 & 3411 & 1. 014 & 1. 000 & 1. 016 \\
\hline $3 d^{8} 4 s^{2} b^{1} \mathrm{D}$ & 2 & 13521 & 13491 & 1. 143 & 1. 000 & 1. 128 \\
\hline $3 d^{10} a^{1} \mathrm{~S}$ & 0 & 14729 & 14729 & & & $\ldots \ldots$ \\
\hline $3 d^{8} 4 s^{2} a^{3} \mathrm{P}$ & $\begin{array}{l}2 \\
1 \\
0\end{array}$ & $\begin{array}{l}15610 \\
15734^{-124} \\
16017^{-283}\end{array}$ & $\begin{array}{l}15632 \\
15726^{-94} \\
15991^{-265}\end{array}$ & $\begin{array}{r}1.356 \\
1.497 \\
\end{array}$ & $\begin{array}{r}1.500 \\
1.500\end{array}$ & $\begin{array}{r}1.370 \\
1.500 \\
-\end{array}$ \\
\hline $3 d^{8} 4 s^{2} a^{1} \mathrm{G}$ & 4 & 22102 & 22098 & 0. 99 & 1. 000 & 1. 000 \\
\hline $3 d^{8} 4 s^{2}{ }^{1} \mathrm{~S}$ & 0 & & 51834 & & & $\ldots \ldots$ \\
\hline
\end{tabular}


Table 8. Transition probabilities of [ $\mathrm{Ni}$ I]

(Units: $\sec ^{-1}$ )

\begin{tabular}{|c|c|c|c|}
\hline \multicolumn{2}{|c|}{ Transition } & $A_{m}$ & $A_{q}$ \\
\hline$a^{3} \mathrm{~F}-a^{3} \mathrm{~F}$ & $\begin{array}{l}4-3 \\
4-2 \\
3-2\end{array}$ & $\begin{array}{c}0.062 \\
.025\end{array}$ & $\begin{array}{l}\text { 6. } 0 \times 10^{-9} \\
\text { 3. } 6 \times 10^{-9} \\
\text { 1. } 1 \times 10^{-9}\end{array}$ \\
\hline$a^{3} \mathbf{F}-a^{3} \mathrm{D}$ & $\begin{array}{l}4-3 \\
3-3 \\
2-3 \\
4-2 \\
3-2 \\
2-2 \\
3-1 \\
2-1\end{array}$ & 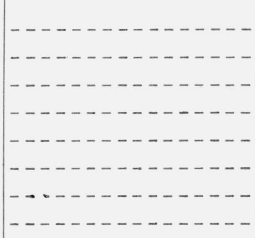 & $\begin{array}{l}\text { 8. } 4 \times 10^{-11} \\
\text { 1. } 2 \times 10^{-7} \\
\text { 2. } 7 \times 10^{-7} \\
\text { 3. } 2 \times 10^{-8} \\
\text { 1. } 8 \times 10^{-9} \\
\text { 3. } 7 \times 10^{-7} \\
\text { 8. } 0 \times 10^{-10} \\
\text { 3. } 9 \times 10^{-9}\end{array}$ \\
\hline $\mathrm{a}^{3} \mathrm{D}-a^{3} \mathrm{D}$ & $\begin{array}{l}3-2 \\
3-1 \\
2-1\end{array}$ & $\begin{array}{c}0.0070 \\
.021\end{array}$ & $\begin{array}{l}\text { 4. } 1 \times 10^{-9} \\
\text { 3. } 0 \times 10^{-8} \\
\text { 1. } 7 \times 10^{-8}\end{array}$ \\
\hline$a^{3} \mathrm{~F}-a^{1} \mathrm{D}$ & $\begin{array}{l}4-2 \\
3-2 \\
2-2\end{array}$ & 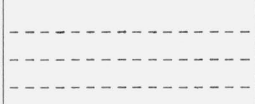 & $\begin{array}{l}\text { 1. } 7 \times 10^{-6} \\
\text { 5. } 4 \times 10^{-7} \\
\text { 6. } 7 \times 10^{-9}\end{array}$ \\
\hline$a^{3} \mathrm{D}-a^{1} \mathrm{D}$ & $\begin{array}{l}3-2 \\
2-2 \\
1-2\end{array}$ & $\begin{array}{l}0.078 \\
.0062 \\
.011\end{array}$ & $\begin{array}{l}\text { 1. } 0 \times 10^{-6} \\
\text { 1. } 8 \times 10^{-7} \\
\text { 3. } 6 \times 10^{-8}\end{array}$ \\
\hline $\begin{array}{c}a^{3} F-b^{1} D \\
(1 F)\end{array}$ & $\begin{array}{l}4-2 \\
3-2 \\
2-2\end{array}$ & $\begin{array}{c}0.39 \\
.17\end{array}$ & $\begin{array}{l}0.0056 \\
\text { 7. } 6 \times 10^{-4} \\
\text { 2. } 0 \times 10^{-4}\end{array}$ \\
\hline $\begin{array}{c}a^{3} \mathrm{D}-b^{1} \mathrm{D} \\
(4 \mathrm{~F})\end{array}$ & $\begin{array}{l}3-2 \\
2-2 \\
1-2\end{array}$ & 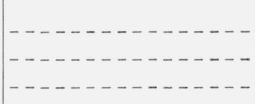 & $\begin{array}{l}0.014 \\
.017 \\
\text { 4. } 5 \times 10^{-4}\end{array}$ \\
\hline $\begin{array}{c}a^{1} \mathrm{D}-b^{1} \mathrm{D} \\
(6 \mathrm{~F})\end{array}$ & $2-2$ & - - - - - - - - - - - & 0.012 \\
\hline$a^{3} \mathrm{~F}-a^{1} \mathrm{~S}$ & $2-0$ & 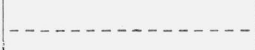 & 1. $8 \times 10^{-4}$ \\
\hline$a^{3} \mathrm{D}-a^{1} \mathrm{~S}$ & $2-0$ & 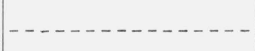 & 0.068 \\
\hline $\begin{array}{c}a^{1} \mathrm{D}-a^{1} \mathrm{~S} \\
(7 \mathrm{~F})\end{array}$ & $2-0$ & - $---------\cdots$ & 0.31 \\
\hline$b^{1} \mathrm{D}-a^{1} \mathrm{~S}$ & $2-0$ & -------------- & 2. $9 \times 10^{-4}$ \\
\hline $\begin{array}{l}a^{3} \mathrm{~F}-a^{3} \mathrm{P} \\
(2 \mathrm{~F})\end{array}$ & $\begin{array}{l}4-2 \\
3-2 \\
2-2 \\
3-1 \\
2-1 \\
2-0\end{array}$ & $\begin{array}{c}0.15 \\
.039 \\
\ldots \ldots 022 \\
\ldots \ldots\end{array}$ & $\begin{array}{l}\text { 0. } 032 \\
.0056 \\
\text { 3. } 98 \times 10^{-4} \\
\text { 0. } 025 \\
.0090 \\
.031\end{array}$ \\
\hline $\begin{array}{c}a^{3} \mathrm{D}-a^{3} \mathrm{P} \\
(5 \mathrm{~F})\end{array}$ & $\begin{array}{l}3-2 \\
2-2 \\
1-2 \\
3-1 \\
2-1 \\
1-1 \\
2-0 \\
1-0\end{array}$ & 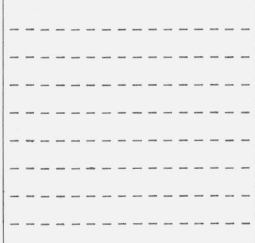 & $\begin{aligned} & 0 . 074 \\
& .018 \\
& .0093 \\
& .092 \\
& .012 \\
& .053 \\
& .19\end{aligned}$ \\
\hline $\begin{array}{c}a^{1} \mathrm{D}-a^{3} \mathrm{P} \\
(8 \mathrm{~F})\end{array}$ & $\begin{array}{l}2-2 \\
2-1 \\
2-0\end{array}$ & 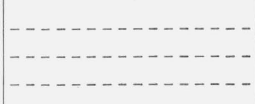 & $\begin{array}{l}0.024 \\
\text { 4. } 7 \times 10^{-4} \\
\text { 1. } 1 \times 10^{-5}\end{array}$ \\
\hline$b^{1} \mathrm{D}-a^{3} \mathrm{P}$ & $\begin{array}{l}2-2 \\
2-1 \\
2-0\end{array}$ & $\begin{array}{r}0.072 \\
.063 \\
-\ldots---\ldots-\ldots\end{array}$ & $\begin{array}{l}\text { 1. } 9 \times 10^{-8} \\
\text { 6. } 9 \times 10^{-7} \\
\text { 1. } 2 \times 10^{-6}\end{array}$ \\
\hline$a^{1} \mathrm{~S}-a^{3} \mathrm{P}$ & $\begin{array}{l}0-2 \\
0-1\end{array}$ & 1. $4 \times 10^{-4}$ & 1. $3 \times 10^{-12}$ \\
\hline
\end{tabular}

TABLE 8. Transition probabilities of [ $\mathrm{Ni} \mathrm{I}]$-Continued

\begin{tabular}{|c|c|c|c|}
\hline \multicolumn{2}{|c|}{ Transition } & $A_{m}$ & $A_{q}$ \\
\hline$a^{3} \mathrm{P}-a^{3} \mathrm{P}$ & $\begin{array}{l}2-1 \\
2-0 \\
1-0\end{array}$ & $\begin{array}{l}3.2 \times 10^{-5} \\
0.0012^{-}\end{array}$ & $\begin{array}{l}8.2 \times 10^{-13} \\
4.5 \times 10^{-10}\end{array}$ \\
\hline $\begin{array}{c}a^{3} \mathrm{~F}-a^{1} \mathrm{G} \\
(3 \mathrm{~F})\end{array}$ & $\begin{array}{l}4-4 \\
3-4 \\
2-4\end{array}$ & $\begin{array}{r}0.32 \\
.16\end{array}$ & $\begin{array}{l}\text { 2. } 2 \times 10^{-4} \\
3.8 \times 10^{-6} \\
\text { 3. } 0 \times 10^{-4}\end{array}$ \\
\hline$a^{3} \mathrm{D}-a^{1} \mathrm{G}$ & $\begin{array}{l}3-4 \\
2-4\end{array}$ & & $\begin{array}{l}7.9 \times 10^{-4} \\
.080\end{array}$ \\
\hline$a^{1} \mathrm{D}-a^{1} \mathrm{G}$ & $2-4$ & & 0.44 \\
\hline$b^{1} \mathrm{D}-a^{1} \mathrm{G}$ & $2-4$ & & $4.1 \times 10^{-4}$ \\
\hline$a^{3} \mathrm{P}-a^{1} \mathrm{G}$ & $2-4$ & & 4. $3 \times 10^{-5}$ \\
\hline$a^{3} \mathrm{~F}-\left({ }^{1} \mathrm{~S}\right)$ & $2-0$ & & 0.17 \\
\hline$a^{3} \mathrm{D}-\left({ }^{1} \mathrm{~S}\right)$ & $2-0$ & & 8. 5 \\
\hline$a^{1} \mathrm{D}-\left({ }^{1} \mathrm{~S}\right)$ & $2-0$ & & 84 \\
\hline$b^{1} \mathrm{D}-\left({ }^{1} \mathrm{~S}\right)$ & $2-0$ & & 9.9 \\
\hline$a^{3} \mathrm{P}-\left({ }^{1} \mathrm{~S}\right)$ & $\begin{array}{l}2-0 \\
1-0\end{array}$ & 5. 4 & 3. 0 \\
\hline
\end{tabular}

for electric quadrupole radiation. These were obtained by extrapolation of results for various stages of ionization of manganese, iron, and nickel which had been obtained in earlier work. The adopted radial integrals are listed in table 6 and the transition probabilities in table 8 .

In $\mathrm{Cu}$ II we are only interested in the $3 d^{10}$ and $3 d^{9} 4 s$ configurations, but the $3 d^{8} 4 s^{2}$ configuration must be included in the calculations. $\mathrm{Cu}$ II has been studied by Racah and Shadmi [15], and we have adopted the numerical values of the parameters which they obtained. The $\mathrm{Ni}$ I work was followed so far as necessary for $\mathrm{Cu}$ II. Examination showed that there are no magnetic dipole transitions between $3 d^{10}$ and $3 d^{9} 4 s$. For electric quadrupole radiation ${ }^{1} \mathrm{~S}_{0}-{ }^{3} \mathrm{D}_{1}$ and ${ }^{1} \mathrm{~S}_{0}-{ }^{3} \mathrm{D}_{3}$ are strictly forbidden. The remaining transitions were computed in the same way as for $\mathrm{Ni}$. The radial integrals for electric quadrupole radiation were estimated by extrapolation of $s_{q}^{-1 / 2}$ from $\mathrm{Fe}$ II [12] and $\mathrm{Ni}$ II [13]. We adopted $\quad s_{q}\left(d^{10}-d^{9} s\right)=-2.0, \quad s_{q}\left(d^{9} s-d^{8} s^{2}\right)=-1.5$. $s_{q}\left(d^{9} s-d^{9} s\right)=+1.0$. The resulting transition probabilities are given in table 9 .

The transition probabilities of $\mathrm{Cu}$ II are of interest in connection with observations of the spectrum of $\eta$ Carinae by Thackeray [17]. He observed the transition $3 d^{10}{ }^{1} \mathrm{~S}_{0}-3 d^{9} 4 s^{1} \mathrm{D}_{2}$ at $\lambda 3806$. Our results show that this line is indeed the strongest forbidden line of $\mathrm{Cu}$ II, and explain the absence of the ${ }^{1} \mathrm{~S}_{0}{ }^{3} \mathrm{D}_{1}$ line. The ${ }^{1} \mathrm{~S}_{0}-{ }^{3} \mathrm{D}_{2}$ line might be observable under suitable conditions; but in $\eta$ Carinae the relatively high densities of the gas (in comparison with planetary nebulae) would enhance the importance of collisional excitation and de-excitation relative to radiative processes, and the ${ }^{1} \mathrm{~S}_{0}-{ }^{3} \mathrm{D}_{2}$ line would then be weaker than the ${ }^{1} \mathrm{~S}_{0}-{ }^{1} \mathrm{D}_{2}$ line by an order of magnitude because of its lower transition probability. 
TABLE 9. Transition probabilities of $[\mathrm{Cu} I \mathrm{I}]$ (Units: $\sec ^{-1}$ )

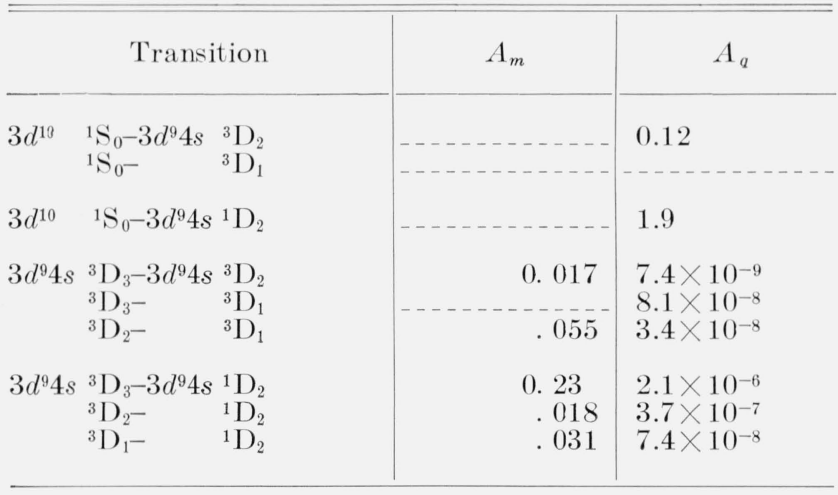

\section{Forbidden Lines in Heavier Atoms $(Z>29)$}

Transition probabilities are available for only a very few forbidden lines of atoms with $Z>29$. The remainder of this paper will be devoted to presenting some additional data on such transitions. The ${ }^{2} \mathrm{D}-{ }^{2} \mathrm{~S}$ doublets in $\mathrm{Rb} \mathrm{I}$ and $\mathrm{Cs}_{\mathrm{I}}$ have been discussed in detail $[4$, p. 256] and will not be further considered here. Results have previously been obtained also for $\mathrm{Pb}$ I [18], Br II [19], I II [20], Kr III [21], Rn II [22], Xe II [22], and Xe III [22].

\section{1. $n p$ and $n p^{5}$ Configurations}

The only observation of the ${ }^{2} \mathrm{P}_{3 / 2}-{ }^{2} \mathrm{P}_{1 / 2}$ transition within an $n p$ configuration appears to be that in Pb II $6 p$ at $\lambda 7099.8$, first observed by Walters [23], and identified and studied by Cole [24]. 'The ${ }^{2} \mathrm{P}_{1 / 2}-{ }^{2} \mathrm{P}_{3 / 2}$ transition in the $n p^{5}$ configuration has been observed in four cases: $\mathrm{Xe}$ II $5 p^{5}$ at $\lambda 9487.8$ and $\mathrm{Rn}$ II $6 p^{5}$ at $\lambda 3235.8$ by Edlén [22], I I $5 p^{5}$ at $\lambda 13149$ by Eshbach and Fisher [25] and Kiess and Corliss [26], and $\mathrm{Br}$ I $4 p^{5}$ at $\lambda 27130$ by J. C. Polanyi [private communication].

Transition probabilities have been calculated from the $L S$-coupling formulae for magnetic dipole line strengths given by Shortley [7] and for electric quadrupole line strengths by Garstang [8, eqs (3), (5), (6) and par. 5]. It is found that for $n p$ and $n p^{5}$ configurations

where

$$
S_{m}=\frac{4}{3} \quad S_{q}=\frac{10}{3} s_{q}^{2}
$$

$$
s_{q}=\frac{2}{5} \int_{0}^{\infty} r^{2} \mathrm{P}^{2}(n p) d r
$$

and the factor $(2 / 5)$ has been included in $s_{q}$ for $p$ electrons (ef $s_{q}$ for $d$ electrons) in accordance with custom [27]. $\mathrm{P}(n p)$ is the radial wave function for an $n p$ electron. The transition probabilities obtained are listed in tables 10 and 11 , where we have included for completeness the two values calculated by Edlén [22]. The estimation of $s_{q}$ is discussed below.
TABLE 10. Transition probabilities for $\mathrm{np}^{2} \mathrm{P}_{\frac{3}{2}} \rightarrow{ }^{2} \mathrm{P}_{\frac{1}{2}}$ (Units: $\mathrm{sec}^{-1}$ )

\begin{tabular}{l|c|c|c}
\hline \hline \multicolumn{1}{r|}{ Ion } & Config. & \multicolumn{1}{|c|}{$A_{m}$} & \multicolumn{1}{|c}{$A_{q}$} \\
\cline { 1 - 1 } & & & \\
\cline { 1 - 1 } Ga I & $4 p$ & 0.0050 & $1.6 \times 10^{-6}$ \\
Ge II & $4 p$ & .049 & $3.1 \times 10^{-5}$ \\
As III & $4 p$ & .23 & $1.9 \times 10^{-4}$ \\
In I & $5 p$ & .097 & $2.7 \times 10^{-4}$ \\
Sn II & $5 p$ & .68 & 0.0035 \\
Sb III & $5 p$ & 2.5 & .017 \\
Tl I & $6 p$ & 4.2 & .11 \\
Pb II & $6 p$ & 25 & 1.3 \\
Bi III & $6 p$ & 80 & 5.9 \\
& & & \\
\hline
\end{tabular}

TABLE 11. Transition probabilities for $n p^{5}{ }^{2} \mathrm{P}_{\frac{1}{2}} \rightarrow{ }^{2} \mathrm{P}_{\frac{3}{2}}$ (Units: $\sec ^{-1}$ )

\begin{tabular}{l|c|c|c}
\hline \hline \multicolumn{1}{r|}{ Ion } & Config. & \multicolumn{1}{|c|}{$\mathrm{A}_{m}$} & \multicolumn{1}{c}{$\mathrm{A}_{q}$} \\
\hline & & & \\
\hline Br I & $4 p^{5}$ & 0.89 & $8.3 \times 10^{-4}$ \\
Kr II & $4 p^{5}$ & 2.8 & 0.0030 \\
Rb III & $4 p^{5}$ & 7.2 & .0094 \\
I I & $5 p^{5}$ & 7.8 & .055 \\
Xe II & $5 p^{5}$ & a 21 & .17 \\
Cs III & $5 p^{5}$ & 48 & .45 \\
Rn II & $6 p^{5}$ & a 530 & 34 \\
& & &
\end{tabular}

a These values have been given previously by Edlén [22].

\section{2. $n p^{2}, n p^{3}$, and $n p^{4}$ Configurations}

Observations of the forbidden line ${ }^{1} \mathrm{~S}_{0}-{ }^{3} \mathrm{P}_{1}$ in $\mathrm{Pb} \mathrm{I}$ $6 p^{2}$ at $\lambda 4618$ played an important part in the history of the subject, for it was by means of observations of the Zeeman effect on this line that Niewodniczanski [28] first demonstrated the occurrence of magnetic dipole radiation. The line ${ }^{1} \mathrm{D}_{2}-{ }^{3} \mathrm{P}_{1}(\lambda 7330)$ was first observed by Walters [23], $\lambda 4618$ by Gieseler and Grotrian [29], and by Sur [30], and ${ }^{1} \mathrm{D}_{2}-{ }^{3} \mathrm{P}_{0}(\lambda 4659)$ and ${ }^{1} \mathrm{~S}_{0}-{ }^{3} \mathrm{P}_{2} \quad(\lambda 5313)$ by Niewodniczanski [31], who also studied $\lambda 4618$ and $\lambda 7330$. Mrozowski [32] found ${ }^{1} \mathrm{D}_{2}-{ }^{3} \mathrm{P}_{2}(\lambda 9250)$. Mrozowski studied the relative intensities $I(4618): I(5313)$ and $I(4659)$ : $I(7330): I(9250)$. The Zeeman effect of $\lambda 4618$, $\lambda 4659, \lambda 5313$, and $\lambda 7330$ was studied by Jenkins and Mrozowski [33]. Gerjuoy [18] gave a detailed discussion of the intensities, to be referred to again below.

Forbidden lines of $\mathrm{Bi}$ II $6 p^{2}$ were observed by Cole and Mrozowski [34], and Cole [35], who obtained ${ }^{1} \mathrm{~S}_{0}-{ }^{3} \mathrm{P}_{1} \quad(\lambda 3241), \quad{ }^{1} \mathrm{~S}_{0}-{ }^{3} \mathrm{P}_{2}(\lambda 3683), \quad{ }^{1} \mathrm{D}_{2}-{ }^{3} \mathrm{P}_{1}(\lambda 4850)$, ${ }^{1} \mathrm{D}_{2}-{ }^{3} \mathrm{P}_{2}(\lambda 5914)$, and ${ }^{3} \mathrm{P}_{1}-{ }^{3} \mathrm{P}_{0}(\lambda 7503)$, and studied their hyperfine structure.

Forbidden lines of $\mathrm{As}$ I $4 p^{3}{ }^{2} \mathrm{P}_{3 / 2}{ }^{4} \mathrm{~S}_{3 / 2}(\lambda 5362)$ and ${ }^{2} \mathrm{P}_{1 / 2}{ }^{4} \mathrm{~S}_{3 / 2}(\lambda 5498)$ and of $\mathrm{Sb}$ I $5 p^{3}{ }^{2} \mathrm{P}_{3 / 2}-{ }^{4} \mathrm{~S}_{3 / 2}(\lambda 5415)$ and ${ }^{2} \mathrm{P}_{1 / 2}{ }^{4} \mathrm{~S}_{3 / 2}(\lambda 6098)$ were observed by Hults and Mrozowski [36]. In $\mathrm{Bi}$ I $6 p^{3}$ Toshniwal [37] found ${ }^{2} \mathrm{D}_{3 / 2}-{ }^{4} \mathrm{~S}_{3 / 2}(\lambda 8755),{ }^{2} \mathrm{D}_{5 / 2}-{ }^{4} \mathrm{~S}_{3 / 2}(\lambda 6476)$, and ${ }^{2} \mathrm{P}_{1 / 2}-{ }^{4} \mathrm{~S}_{3 / 2}$ $(\lambda 4615)$, and Mrozowski [38] made a study of these lines together with ${ }^{2} \mathrm{P}_{3 / 2}-{ }^{4} \mathrm{~S}_{3 / 2}(\lambda 3014),{ }^{2} \mathrm{P}_{3 / 2}-{ }^{2} \mathrm{D}_{3 / 2}$ 
( $\lambda 4597)$, and ${ }^{2} \mathrm{P}_{3 / 2}{ }^{2} \mathrm{D}_{5 / 2}(\lambda 5640)$ which he found. Mrozowski made hyperfine structure observations which proved that all these $\mathrm{Bi}$ I transitions are predominantly magnetic dipole radiation. For $\lambda 6476$, the best resolved line, electric quadrupole radiation was less than 0.15 of the total. Mrozowski also pointed out the need for more laboratory intensity measurements on the forbidden lines of $\mathrm{Bi}$ I and other atoms.

Ruedy and Gibbs [39] found the lines ${ }^{1} \mathrm{~S}_{0}-{ }^{1} \mathbf{D}_{2}$ $(\lambda 7768)$ and ${ }^{1} \mathrm{~S}_{0}-{ }^{3} \mathrm{P}_{1}(\lambda 4887)$ in Se I $4 p^{4}$. Niewodniczanski and Lipinski [40] found ${ }^{1} \mathrm{~S}_{0}{ }^{-1} \mathrm{D}_{2}$ ( $\left.\lambda 7909\right)$, ${ }^{1} \mathrm{~S}_{0}-{ }^{3} \mathrm{P}_{1} \quad(\lambda 5420)$, and ${ }^{1} \mathrm{~S}_{0}{ }^{3} \mathrm{P}_{2}(\lambda 4309)$ in TeI $5 p^{4}$, $\lambda 5420$ being much stronger than the others. Mrozowski [41] observed ${ }^{1} \mathrm{~S}_{0}-{ }^{3} \mathrm{P}_{1}(\lambda 3862),{ }^{1} \mathrm{D}_{2}{ }^{-3} \mathrm{P}_{2}$ $(\lambda 4611)$, and ${ }^{3} \mathrm{P}_{1}-{ }^{3} \mathrm{P}_{2}(\lambda 5940)$ in $\mathrm{PoI} 6 p^{4}$. Martin and Tech [19] found ${ }^{1} \mathrm{~S}_{0}{ }^{3} \mathrm{P}_{1}(\lambda 4042)$ and ${ }^{1} \mathrm{D}_{2}{ }^{3} \mathrm{P}_{2}$ $(\lambda 8270)$ in $\mathrm{BrII} 4 p^{4}$. Martin and Corliss [20] found ${ }^{1} \mathrm{~S}_{0}-{ }^{3} \mathrm{P}_{1}(\lambda 4460)$ and ${ }^{1} \mathrm{D}_{2}-{ }^{3} \mathrm{P}_{2}(\lambda 7283)$ in III $5 p^{4}$ and Edlén [22] found ${ }^{1} \mathrm{D}_{2}-{ }^{3} \mathrm{P}_{2}(\lambda 5846.3)$ and ${ }^{3} \mathrm{P}_{1}-{ }^{3} \mathrm{P}_{2}$ $(\lambda 10206.5)$ in XeIII $5 p^{4}$. Kr III ${ }^{1} \mathrm{D}_{2}-{ }^{3} \mathrm{P}_{2}(\lambda 6827)$ may be present in spectra of RS Ophiuchi [54], but later work cast considerable doubt on the identification [61].

General formulae for line strengths and transition probabilities in $p^{2}, p^{3}$, and $p^{4}$ configurations were given by Shortley, Aller, Baker, and Menzel [27].

TABLE 12. Parameters in $\mathrm{p}^{2}$ configurations

(Units: $\mathrm{cm}^{-1}$ )

\begin{tabular}{|c|c|c|c|c|}
\hline Doncouto & Ge I & $\mathrm{Sn} \mathrm{I}$ & $\mathrm{Pb} \mathrm{I}$ & Bi II \\
\hline & $4 p^{2}$ & $5 p^{2}$ & $6 p^{2}$ & $6 p^{2}$ \\
\hline $\begin{array}{l}\mathrm{E}\left({ }^{3} \mathrm{P}\right) \\
\mathrm{E}\left({ }^{1} \mathrm{D}\right) \\
\mathrm{E}\left({ }^{1} \mathrm{~S}\right) \\
\zeta\end{array}$ & $\begin{array}{r}1023 \\
7050 \\
16263 \\
921.5\end{array}$ & $\begin{array}{r}2839 \\
8070 \\
16554 \\
2247\end{array}$ & $\begin{array}{r}11538 \\
16930 \\
25205 \\
7355\end{array}$ & $\begin{array}{l}19275 \\
25808 \\
36618 \\
11789\end{array}$ \\
\hline
\end{tabular}

$$
\begin{aligned}
& \Psi\left({ }^{1} \mathrm{D}_{2}\right)=a \Phi\left({ }^{1} \mathrm{D}_{2}\right)+b \Phi\left({ }^{3} \mathrm{P}_{2}\right) \\
& \Psi\left({ }^{3} \mathrm{P}_{2}\right)=-b \Phi\left({ }^{1} \mathrm{D}_{2}\right)+a \Phi\left({ }^{3} \mathrm{P}_{2}\right) \\
& \Psi\left({ }^{3} \mathrm{P}_{1}\right)=\Phi\left({ }^{3} \mathrm{P}_{1}\right) \\
& \Psi\left({ }^{3} \mathrm{P}_{0}\right)=c \Phi\left({ }^{3} \mathrm{P}_{0}\right)+d \Phi\left({ }^{1} \mathrm{~S}_{0}\right) \\
& \Psi\left({ }^{1} \mathrm{~S}_{0}\right)=-d \Phi\left({ }^{3} \mathrm{P}_{0}\right)+c \Phi\left({ }^{1} \mathrm{~S}_{0}\right)
\end{aligned}
$$

We have used their line strength formulae, but the parameters have been determined in the manner used by Garstang [e.g., 42]. The electrostatic parameters $\mathrm{E}\left({ }^{3} \mathrm{P}\right), \mathrm{E}\left({ }^{1} \mathrm{D}\right)$ and $\mathrm{E}\left({ }^{1} \mathrm{~S}\right)$ (for $p^{2}$ and $p^{4}$ configurations) or $\mathrm{E}\left({ }^{4} \mathrm{~S}\right), \mathrm{E}\left({ }^{2} \mathrm{D}\right)$, and $\mathrm{E}\left({ }^{2} \mathrm{P}\right)$ (for $p^{3}$ configurations) and the spin-orbit parameter $\zeta$ have been treated as adjustable. They have been determined by fitting the theory [4, p. 268] to the observed energy levels by trial and error followed by one or more least squares adjustments. The energies were taken from [2] except for III [20] and $\mathrm{Br}$ II [19]. The adopted parameters are listed in tables 12,17 , and 21 . The intermediate coupling wave functions are written in the form given by Shortley, Aller, Baker, and Menzel [27]:

for $p^{2}$ and $p^{4}$ configurations, and

$$
\begin{aligned}
& \Psi\left({ }^{2} \mathrm{D}_{5 / 2}\right)=\Phi\left({ }^{2} \mathrm{D}_{5 / 2}\right) \\
& \Psi\left({ }^{2} \mathrm{D}_{3 / 2}\right)=a \Phi\left({ }^{2} \mathrm{P}_{3 / 2}\right)+b \Phi\left({ }^{4} \mathrm{~S}_{3 / 2}\right)+c \Phi\left({ }^{2} \mathrm{D}_{3 / 2}\right) \\
& \Psi\left({ }^{4} \mathrm{~S}_{3 / 2}\right)=a^{\prime} \Phi\left({ }^{2} \mathrm{P}_{3 / 2}\right)+b^{\prime} \Phi\left({ }^{4} \mathrm{~S}_{3 / 2}\right)+c^{\prime} \Phi\left({ }^{2} \mathrm{D}_{3 / 2}\right) \\
& \Psi\left({ }^{2} \mathrm{P}_{3 / 2}\right)=a^{\prime \prime} \Phi\left({ }^{2} \mathrm{P}_{3 / 2}\right)+b^{\prime \prime} \Phi\left({ }^{4} \mathrm{~S}_{3 / 2}\right)+c^{\prime \prime} \Phi\left({ }^{2} \mathrm{D}_{3 / 2}\right) \\
& \Psi\left({ }^{2} \mathrm{P}_{1 / 2}\right)=\Phi\left({ }^{2} \mathrm{P}_{1 / 2}\right)
\end{aligned}
$$

for $p^{3}$ configurations, where $\Phi$ and $\Psi$ denote respectively the LS-coupling and intermediate coupling functions. The observed and calculated energies are listed in tables $13,18,22,23$, and 24 , and the coefficients in the wave functions in tables 14 and 19 . One check which can be applied in a few cases is to calculate the Landé $g$-values and compare them with observed values. This was done for Ge I, Sn I, and $\mathrm{Pb} \mathrm{I}$ and the results are given in table 15 . The general agreement of observed and calculated energy levels and Landé $g$-factors is very satisfactory, and lead us to think that the intermediate coupling theory provides a satisfactory representation of the atomic electron configurations. The radial integrals $s_{q}$ (defined as above with the $2 / 5$ factor) needed in the formulae of [27] for electric quadrupole radiation were estimated as discussed below. Then the transition probabilities were calculated, and are given in

\begin{tabular}{|c|c|c|c|c|c|c|c|c|c|c|c|c|}
\hline \multirow{2}{*}{ Level } & \multicolumn{3}{|c|}{ Ge I $\left(4 p^{2}\right)$} & \multicolumn{3}{|c|}{ Sn I $\left(5 p^{2}\right)$} & \multicolumn{3}{|c|}{$\mathrm{Pb}$ I $\left(6 p^{2}\right)$} & \multicolumn{3}{|c|}{ Bi II $\left(6 p^{2}\right)$} \\
\hline & $\mathrm{O}$ & C & $\mathrm{O}-\mathrm{C}$ & $\mathrm{O}$ & $\mathrm{C}$ & $\mathrm{O}-\mathrm{C}$ & $\mathrm{O}$ & $\mathrm{C}$ & $\mathrm{O}-\mathrm{C}$ & $\mathrm{O}$ & $\mathrm{C}$ & $\mathrm{O}-\mathrm{C}$ \\
\hline $\begin{array}{l}{ }^{3} \mathrm{P}_{0} \\
{ }^{3} \mathrm{P}_{1} \\
{ }^{3} \mathrm{P}_{2} \\
{ }^{1} \mathrm{D}_{2} \\
{ }^{1} \mathrm{~S}_{0}\end{array}$ & $\begin{array}{r}0 \\
557 \\
1410 \\
7125 \\
16367\end{array}$ & $\begin{array}{r}-3 \\
562 \\
1408 \\
7125 \\
16367\end{array}$ & $\begin{array}{r}3 \\
-5 \\
2 \\
0 \\
0\end{array}$ & $\begin{array}{r}0 \\
1692 \\
3428 \\
8613 \\
17163\end{array}$ & $\begin{array}{r}-17 \\
1715 \\
3420 \\
8613 \\
17163\end{array}$ & $\begin{array}{r}17 \\
-23 \\
8 \\
0 \\
0\end{array}$ & $\begin{array}{r}0 \\
7819 \\
10650 \\
21458 \\
29467\end{array}$ & $\begin{array}{r}-94 \\
7860 \\
10802 \\
21344 \\
29482\end{array}$ & $\begin{array}{r}94 \\
-41 \\
-152 \\
114 \\
-15\end{array}$ & $\begin{array}{r}0 \\
13324 \\
17030 \\
33936 \\
44173\end{array}$ & $\begin{array}{r}-87 \\
13380 \\
17147 \\
33831 \\
44190\end{array}$ & $\begin{array}{r}87 \\
-56 \\
-117 \\
107 \\
-17\end{array}$ \\
\hline
\end{tabular}
tables 16,20 , and 25 .

It should be mentioned that a number of authors have attempted fitting theory to observation for $p^{n}$ configurations, for example Te I, I II, and Xe III [20], $\mathrm{Pb}$ I [18, 43], Brir [19], Ge I [44], Sn I [45], and possibly others. Most assumed the Slater ratio between the term intervals, and thus had one fewer adjustable

TABLE 13. Observed and calculated energy levels in $\mathrm{p}^{2}$ configurations

(Units: $\mathrm{cm}^{-1}$ ) 
TABLE 14. Coefficients in intermediate coupling wave functions ( $\mathrm{p}^{2}$ and $\mathrm{p}^{4}$ configurations)

\begin{tabular}{ll|r|r|r|r}
\hline \multicolumn{2}{r}{ Ion } & & & & \\
& & & & \\
& & & & \\
Ge I & $4 p^{2}$ & 0.9934 & 0.1148 & 0.9968 & 0.0799 \\
Sn I & $5 p^{2}$ & .9463 & .3232 & .9821 & .1883 \\
Pb I & $6 p^{2}$ & .7624 & .6471 & .9249 & .3803 \\
Bi II & $6 p^{2}$ & .7206 & .6933 & .9106 & .4133 \\
Se I & $4 p^{4}$ & .9910 & -.1342 & .9916 & -.1297 \\
Br II & $4 p^{4}$ & .9863 & -.1652 & .9861 & -.1663 \\
Kr III & $4 p^{4}$ & .9807 & -.1953 & .9784 & -.2065 \\
Te I & $5 p^{4}$ & .9617 & -.2743 & .9471 & -.3211 \\
I II & $5 p^{4}$ & .9523 & -.3050 & .9277 & -.3732 \\
Xe III & $5 p^{4}$ & .9392 & -.3435 & .9039 & -.4277 \\
Po I & $6 p^{4}$ & .8921 & -.4519 & .7495 & -.6620 \\
\end{tabular}

TABLE 15. Landé g-factors in $\mathrm{p}^{2}$ configurations

\begin{tabular}{|c|c|c|c|c|c|c|c|c|c|c|}
\hline \multirow{2}{*}{ Level } & \multirow{2}{*}{$\begin{array}{c}L S \\
\text { coupling }\end{array}$} & \multicolumn{3}{|c|}{ Ge I } & \multicolumn{3}{|c|}{ Sn I } & \multicolumn{3}{|c|}{$\mathrm{Pb} \mathrm{I}$} \\
\hline & & Observed & Calculated & $\mathrm{O}-\mathrm{C}$ & Observed & Calculated & $\mathrm{O}-\mathrm{C}$ & Observed & Calculated & $\mathrm{O}-\mathrm{C}$ \\
\hline $\begin{array}{l}{ }^{3} \mathrm{P}_{1} \ldots \ldots \\
{ }^{3} \mathrm{P}_{2 \ldots \ldots} \ldots \ldots \\
{ }^{1} \mathrm{D}_{2 \ldots \ldots} \ldots \ldots-\end{array}$ & $\begin{array}{l}\text { 1. } 500 \\
\text { 1. } 500 \\
1.000\end{array}$ & $\begin{array}{r}\text { 1. } 476 \\
\text { 1. } 514 \\
.989\end{array}$ & $\begin{array}{l}\text { 1. } 500 \\
\text { 1. } 493 \\
\text { 1. } 007\end{array}$ & $\begin{array}{r}-0.024 \\
.021 \\
-.018\end{array}$ & $\begin{array}{l}\text { 1. } 502 \\
\text { 1. } 452 \\
\text { 1. } 052\end{array}$ & $\begin{array}{l}\text { 1. } 500 \\
\text { 1. } 448 \\
\text { 1. } 052\end{array}$ & $\begin{array}{l}0.002 \\
.004 \\
0\end{array}$ & $\begin{array}{l}\text { 1. } 501 \\
\text { 1. } 269 \\
\text { 1. } 230\end{array}$ & $\begin{array}{l}\text { 1. } 500 \\
\text { 1. } 291 \\
\text { 1. } 209\end{array}$ & $\begin{array}{r}0.001 \\
-.022 \\
.021\end{array}$ \\
\hline
\end{tabular}

TABLE 16. Transition probabilities for $\mathrm{p}^{2}$ configurations

\begin{tabular}{|c|c|c|c|c|c|}
\hline Transition & Type & Ge I & $\mathrm{Sn} I$ & $\mathrm{~Pb} \mathrm{I}^{\mathrm{a}}$ & BiII \\
\hline $\begin{array}{l}{ }^{1} \mathrm{~S}_{0}-{ }^{1} \mathrm{D}_{2} \\
{ }^{1} \mathrm{~S}_{0}{ }^{3} \mathrm{P}_{2} \\
{ }^{1} \mathrm{~S}_{0}-{ }^{3} \mathrm{P}_{1} \\
{ }^{1} \mathrm{D}_{2}-{ }^{3} \mathrm{P}_{2} \\
{ }^{1} \mathrm{D}_{2}-{ }^{3} \mathrm{P}_{1} \\
{ }^{1} \mathrm{D}_{2}-{ }^{3} \mathrm{P}_{0} \\
{ }^{3} \mathrm{P}_{2}-{ }^{-3} \mathrm{P}_{1} \\
{ }^{3} \mathrm{P}_{2}-{ }^{3} \mathrm{P}_{0} \\
{ }^{3} \mathrm{P}_{1}-{ }^{3} \mathrm{P}_{0}\end{array}$ & 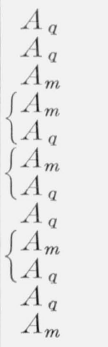 & $\begin{array}{l}1.1 \\
0.068 \\
1.0 \\
0.097 \\
.0010 \\
0.050 \\
3.0 \times 10^{-4} \\
3.0 \times 10^{-5} \\
0.0082 \\
8.3 \times 10^{-7} \\
4.6 \times 10^{-6} \\
0.0031\end{array}$ & $\begin{array}{l}0.95 \\
0.57 \\
7.0 \\
0.52 \\
.0061 \\
0.46 \\
.0043 \\
8.1 \times 10^{-5} \\
0.062 \\
3.6 \times 10^{-5} \\
5.9 \times 10^{-4} \\
0.083\end{array}$ & $\begin{array}{l}0.48 \\
10 \\
78 \\
12 \\
0.60 \\
14 \\
0.46 \\
0.0017 \\
0.18 \\
2.5 \times 10^{-4} \\
0.21 \\
7.3\end{array}$ & $\begin{array}{l}1.1 \\
47 \\
270 \\
48 \\
3.7 \\
56 \\
2.8 \\
0.039 \\
0.35 \\
5.6 \times 10^{-4} \\
1.6 \\
35\end{array}$ \\
\hline
\end{tabular}

a In substantial agreement with Gerjuoy [18], allowing for difference in $s_{q}$.

TABLE 17. Parameters in $\mathrm{p}^{3}$ configurations

(Units: $\mathrm{cm}^{-1}$ )

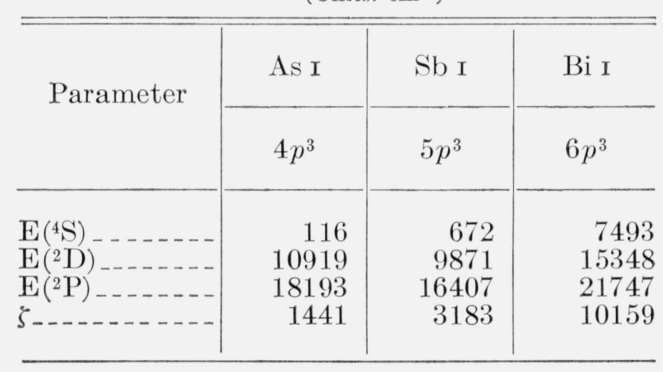


TABLE 18. Observed and calculated energy levels in $\mathrm{p}^{3}$ configurations

(Units: $\mathrm{cm}^{-1}$ )

\begin{tabular}{|c|c|c|c|c|c|c|c|c|c|}
\hline \multirow{2}{*}{ Level } & \multicolumn{3}{|c|}{ As I $\left(4 p^{3}\right)$} & \multicolumn{3}{|c|}{$\mathrm{Sb}$ I $\left(5 p^{3}\right)$} & \multicolumn{3}{|c|}{$\mathrm{Bi}$ I $\left(6 p^{3}\right)$} \\
\hline & $\mathrm{O}$ & $\mathrm{C}$ & $\mathrm{O}-\mathrm{C}$ & $\mathrm{O}$ & $\mathrm{C}$ & $\mathrm{O}-\mathrm{C}$ & $\mathrm{O}$ & $\mathrm{C}$ & $\mathrm{O}-\mathrm{C}$ \\
\hline $\begin{array}{l}{ }^{4} \mathrm{~S}_{3 / 2} \\
{ }^{2} \mathrm{D}_{3 / 2} \\
{ }^{2} \mathrm{D}_{5 / 2} \\
{ }^{2} \mathrm{P}_{1 / 2} \\
{ }^{2} \mathrm{P}_{3 / 2}\end{array}$ & $\begin{array}{r}0 \\
10593 \\
10915 \\
18186 \\
18648\end{array}$ & $\begin{array}{r}0 \\
10587 \\
10919 \\
18193 \\
18641\end{array}$ & $\begin{array}{r}0 \\
6 \\
-4 \\
-7 \\
7\end{array}$ & $\begin{array}{r}0 \\
8512 \\
9854 \\
16396 \\
18465\end{array}$ & $\begin{array}{r}2 \\
8495 \\
9871 \\
16407 \\
18453\end{array}$ & $\begin{array}{r}-2 \\
17 \\
-17 \\
-11 \\
12\end{array}$ & $\begin{array}{r}0 \\
11419 \\
15438 \\
21661 \\
33165\end{array}$ & $\begin{array}{r}-129 \\
11652 \\
15348 \\
21747 \\
33064\end{array}$ & $\begin{array}{r}129 \\
-233 \\
90 \\
-86 \\
101\end{array}$ \\
\hline
\end{tabular}

TABLE 20. Transition probabilities for $\mathrm{p}^{3}$ configurations

(Units: $\sec ^{-1}$ )

TABLE 19. Coefficients in intermediate coupling wave functions ( $\mathrm{p}^{3}$ configurations)

\begin{tabular}{|c|c|c|c|}
\hline & As I & $\mathrm{Sb} \mathrm{I}$ & Bi I \\
\hline & $4 p^{3}$ & $5 p^{3}$ & $6 p^{3}$ \\
\hline$a$ & -0.2021 & -0.3572 & -0.2466 \\
\hline$b$ & -.0279 & -.1453 & -.6032 \\
\hline$c$ & .9789 & .9227 & .7585 \\
\hline$a^{\prime}$ & -.0800 & -. 2053 & -.5494 \\
\hline$b^{\prime}$ & .9968 & .9759 & .7318 \\
\hline$c^{\prime}$ & 0119 & .0742 & 4033 \\
\hline$a^{\prime \prime}$ & 9761 & .9113 & .7984 \\
\hline$b^{\prime \prime}$ & .0760 & .1629 & .3172 \\
\hline$c^{\prime \prime}$ & .2038 & .3781 & .5118 \\
\hline
\end{tabular}

\begin{tabular}{|c|c|c|c|c|}
\hline Transition & Туре & As I & $\mathrm{Sb}$ I & $\mathrm{Bi} \mathrm{I}$ \\
\hline $\begin{array}{l}{ }^{2} \mathrm{P}_{3 / 2}-{ }^{2} \mathrm{P}_{1 / 2} \\
{ }^{2} \mathrm{P}_{3 / 2}-{ }^{2} \mathrm{D}_{5 / 2} \\
{ }^{2} \mathrm{P}_{3 / 2}-{ }^{2} \mathrm{D}_{3 / 2} \\
{ }^{2} \mathrm{P}_{1 / 2}-{ }^{2} \mathrm{D}_{5 / 2} \\
{ }^{2} \mathrm{P}_{1 / 2}-{ }^{2} \mathrm{D}_{3 / 2} \\
{ }^{2} \mathrm{P}_{3 / 2}-{ }^{4} \mathrm{~S}_{3 / 2} \\
{ }^{2} \mathrm{P}_{1 / 2}-{ }^{4} \mathrm{~S}_{3 / 2} \\
{ }^{2} \mathrm{D}_{5 / 2}-{ }^{2} \mathrm{D}_{3 / 2} \\
{ }^{2} \mathrm{D}_{5 / 2}-{ }^{4} \mathrm{~S}_{3 / 2} \\
{ }^{2} \mathrm{D}_{3 / 2}-{ }^{4} \mathrm{~S}_{3 / 2}\end{array}$ & $\begin{array}{l}\left\{\begin{array}{l}A_{m} \\
A_{q}\end{array}\right. \\
\left\{\begin{array}{l}A_{m} \\
A_{q}\end{array}\right. \\
\left\{\begin{array}{l}A_{m} \\
A_{q}\end{array}\right. \\
\begin{array}{l}A_{q} \\
A_{m} \\
A_{q}\end{array} \\
\left\{\begin{array}{l}A_{m} \\
A_{q}\end{array}\right. \\
\left\{\begin{array}{l}A_{m} \\
A_{q}\end{array}\right. \\
\left\{\begin{array}{l}A_{m} \\
A_{q}\end{array}\right. \\
\left\{\begin{array}{l}A_{m} \\
A_{q}\end{array}\right. \\
\left\{\begin{array}{l}A_{m} \\
A_{q}\end{array}\right.\end{array}$ & $\begin{array}{l}8.4 \times 10^{-4} \\
1.9 \times 10^{-9} \\
0.31 \\
.13 \\
0.61 \\
.062 \\
0.059 \\
.32 \\
.10 \\
1.6 \\
1.0 \times 10^{-4} \\
0.69 \\
.0012 \\
3.4 \times 10^{-4} \\
4.7 \times 10^{-10} \\
0.0020 \\
.0033 \\
0.073 \\
.0019\end{array}$ & $\begin{array}{l}0.065 \\
2.0 \times 10^{-5} \\
1.5 \\
0.33 \\
4.0 \\
0.17 \\
.058 \\
1.1 \\
0.19 \\
5.2 \\
7.8 \times 10^{-4} \\
3.3 \\
0.048 \\
.022 \\
3.2 \times 10^{-6} \\
0.056 \\
.022 \\
1.1 \\
0.0075\end{array}$ & $\begin{array}{l}8.6 \\
0.21 \\
23 \\
10 \\
120 \\
4.5 \\
0.050 \\
1.2 \\
0.51 \\
7.3 \\
0.27 \\
55 \\
6.2 \\
0.40 \\
4.0 \times 10^{-4} \\
6.4 \\
1.6 \\
31 \\
0.21\end{array}$ \\
\hline
\end{tabular}

TABle 21. Parameters in $\mathrm{p}^{4}$ configurations

(Units: $\mathrm{cm}^{-1}$ )

\begin{tabular}{|c|c|c|c|c|c|c|c|}
\hline \multirow{2}{*}{ Parameter } & Se I & Br II & Kr III & Te I & I II & Xe III & Po I \\
\hline & $4 p^{4}$ & $4 p^{4}$ & $4 p^{4}$ & $5 p^{4}$ & $5 p^{4}$ & $5 p^{4}$ & $6 p^{4}$ \\
\hline $\begin{array}{l}\mathrm{E}\left({ }^{3} \mathrm{P}\right) \ldots \\
\mathrm{E}\left({ }^{1} \mathrm{D}\right) \ldots \ldots \\
\mathrm{E}\left({ }^{1} \mathrm{~S}\right) \ldots \ldots \\
5_{\ldots \ldots} \ldots \ldots \ldots\end{array}$ & $\begin{array}{r}1075 \\
9402 \\
22112 \\
1808\end{array}$ & $\begin{array}{r}1728 \\
11759 \\
27202 \\
2785\end{array}$ & $\begin{array}{r}2549 \\
14084 \\
31890 \\
3965\end{array}$ & $\begin{array}{r}2735 \\
9765 \\
21293 \\
3954\end{array}$ & $\begin{array}{r}4133 \\
12453 \\
26310 \\
5617\end{array}$ & $\begin{array}{r}5797 \\
15083 \\
32044 \\
7906\end{array}$ & $\begin{array}{l}10611 \\
17250 \\
27295 \\
12341\end{array}$ \\
\hline
\end{tabular}


TABLE 22. Observed and calculated energy levels in $4 \mathrm{p}^{4}$ configurations

(Units: $\mathrm{cm}^{-1}$ )

\begin{tabular}{|c|c|c|c|c|c|c|c|c|c|}
\hline \multirow{2}{*}{ Level } & \multicolumn{3}{|c|}{ Se I } & \multicolumn{3}{|c|}{ Br II } & \multicolumn{3}{|c|}{ Kr III } \\
\hline & $\mathrm{O}$ & $\mathrm{C}$ & $\mathrm{O}-\mathrm{C}$ & $\mathrm{O}$ & $\mathrm{C}$ & $\mathrm{O}-\mathrm{C}$ & $\mathrm{O}$ & $\mathrm{C}$ & $\mathrm{O}-\mathrm{C}$ \\
\hline $\begin{array}{l}{ }^{3} \mathrm{P}_{2} \\
{ }^{3} \mathrm{P}_{1} \\
{ }^{3} \mathrm{P}_{0} \\
{ }^{1} \mathrm{D}_{2} \\
{ }^{1} \mathrm{~S}_{0}\end{array}$ & $\begin{array}{r}0 \\
1989 \\
2534 \\
9576 \\
22446\end{array}$ & $\begin{array}{r}-3 \\
1979 \\
2549 \\
9576 \\
22446\end{array}$ & $\begin{array}{r}3 \\
10 \\
-15 \\
0 \\
0\end{array}$ & $\begin{array}{r}0 \\
3136 \\
3838 \\
12089 \\
27867\end{array}$ & $\begin{array}{r}6 \\
3120 \\
3849 \\
12089 \\
27866\end{array}$ & $\begin{array}{r}-6 \\
16 \\
-11 \\
0 \\
1\end{array}$ & $\begin{array}{r}0 \\
4548 \\
5313 \\
14644 \\
33079\end{array}$ & $\begin{array}{r}8 \\
4531 \\
5330 \\
14643 \\
33074\end{array}$ & $\begin{array}{r}-8 \\
17 \\
-17 \\
1 \\
5\end{array}$ \\
\hline
\end{tabular}

TABLE 23. Observed and calculated energy levels in $5 \mathrm{p}^{4}$ configurations

(Units: $\mathrm{cm}^{-1}$ )

\begin{tabular}{|c|c|c|c|c|c|c|c|c|c|}
\hline \multirow{2}{*}{ Level } & \multicolumn{3}{|c|}{$\mathrm{Te} \mathrm{I}$} & \multicolumn{3}{|c|}{ I II } & \multicolumn{3}{|c|}{$\mathrm{Xe}$ III } \\
\hline & $\mathrm{O}$ & $\mathrm{C}$ & $\mathrm{O}-\mathrm{C}$ & $\mathrm{O}$ & $\mathrm{C}$ & $\mathrm{O}-\mathrm{C}$ & $\mathrm{O}$ & $\mathrm{C}$ & $\mathrm{O}-\mathrm{C}$ \\
\hline $\begin{array}{l}{ }^{3} \mathrm{P}_{2} \\
{ }^{3} \mathrm{P}_{1} \\
{ }^{3} \mathrm{P}_{0} \\
{ }^{1} \mathrm{D}_{2} \\
{ }^{1} \mathrm{~S}_{0}\end{array}$ & $\begin{array}{r}0 \\
4751 \\
4707 \\
10559 \\
23199\end{array}$ & $\begin{array}{r}-39 \\
4712 \\
4794 \\
10562 \\
23188\end{array}$ & $\begin{array}{r}39 \\
39 \\
-87 \\
-3 \\
11\end{array}$ & $\begin{array}{r}0 \\
7087 \\
6448 \\
13727 \\
29501\end{array}$ & $\begin{array}{r}53 \\
6942 \\
6555 \\
13725 \\
29505\end{array}$ & $\begin{array}{r}-53 \\
145 \\
-107 \\
2 \\
-4\end{array}$ & $\begin{array}{r}0 \\
9795 \\
8131 \\
17100 \\
37398\end{array}$ & $\begin{array}{r}-201 \\
9750 \\
8414 \\
17128 \\
37333\end{array}$ & $\begin{array}{r}201 \\
45 \\
-283 \\
-28 \\
65\end{array}$ \\
\hline
\end{tabular}

TABLE 24. Observed and calculated energy levels in Po I $\left(6 \mathrm{p}^{4}\right)$

\begin{tabular}{l|r|r|r}
\multicolumn{3}{|c}{ (Units: $\left.\mathrm{cm}^{-1}\right)$} \\
\hline \hline Level & Observed & Calculated & O-C \\
\hline & & & \\
\hline${ }^{3} \mathrm{P}_{2}$ & 0 & 13 & -13 \\
${ }^{3} \mathrm{P}_{1}$ & 16831 & 16782 & 49 \\
${ }^{3} \mathrm{P}_{0}$ & 7514 & 7546 & -32 \\
${ }^{1} \mathrm{D}_{2}$ & 21679 & 21671 & 8 \\
${ }^{1} \mathrm{~S}_{0}$ & 42718 & 42710 & 8 \\
\hline
\end{tabular}

TABLE 25. Transition probabilities for $\mathrm{p}^{4}$ configurations

(Units: $\sec ^{-1}$ )

\begin{tabular}{|c|c|c|c|c|c|c|c|c|}
\hline Transition & Type & Se I & $\mathrm{Br}$ II & Kr III & Te I & I II & Xe III & Po I \\
\hline $\begin{array}{l}{ }^{1} \mathrm{~S}_{0}-{ }^{1} \mathrm{D}_{2} \\
{ }^{1} \mathrm{~S}_{0}-{ }^{3} \mathrm{P}_{2} \\
{ }^{1} \mathrm{~S}_{0}-{ }^{-3} \mathrm{P}_{1} \\
{ }^{1} \mathrm{D}_{2}-{ }^{3} \mathrm{P}_{2} \\
{ }^{1} \mathrm{D}_{2}-{ }^{3} \mathrm{P}_{1} \\
{ }^{1} \mathrm{D}_{2}-{ }^{-3} \mathrm{P}_{0} \\
{ }^{e}{ }^{3} \mathrm{P}_{0}-3 \mathrm{P}_{1} \\
{ }^{3} \mathrm{P}_{0}-{ }^{-3} \mathrm{P}_{2} \\
{ }^{3} \mathrm{P}_{1}-{ }^{-3} \mathrm{P}_{2}\end{array}$ & $\begin{array}{l}\begin{array}{l}A_{q} \\
A_{q}\end{array} \\
A_{m}\end{array}$ & $\begin{array}{l}2.3 \\
0.18 \\
7.7 \\
0.62 \\
.0074 \\
.11 \\
3.5 \times 10^{-4} \\
9.2 \times 10^{-5} \\
0.0085 \\
\text { 1. } 8 \times 10^{-4} \\
\text { 0. } 17 \\
\text { 3. } 9 \times 10^{-5}\end{array}$ & $\begin{array}{l}\text { 4. } 0 \\
\text { 0. } 43 \\
\text { a } 23 \\
\text { a } 1.9 \\
\quad 0.022 \\
\quad .26 \\
\quad 7.2 \times 10^{-4} \\
\text { 2. } 1 \times 10^{-4} \\
\text { 0. } 018 \\
\text { 8. } 7 \times 10^{-4} \\
\text { 0. } 67 \\
\text { 2. } 2 \times 10^{-4}\end{array}$ & $\begin{array}{l}\text { 4. } 5 \\
0.69 \\
53 \\
\text { c } 4.7 \\
\text { 0. } 043 \\
\text { c } 0.53 \\
.0010 \\
3.7 \times 10^{-4} \\
0.023 \\
.0025 \\
\text { 2. } 0 \\
\text { 7. } 6 \times 10^{-4}\end{array}$ & $\begin{array}{l}\text { 3. } 1 \\
0.79 \\
37 \\
3.3 \\
0.077 \\
.20 \\
\text { 6. } 0 \times 10^{-4} \\
4.7 \times 10^{-4} \\
\text { 1. } 4 \times 10^{-6} \\
0.0073 \\
2.2 \\
0.0044\end{array}$ & $\begin{aligned} 5.5 \\
1.6 \\
\mathrm{~b} 84 \\
\mathrm{~b} 8.8 \\
0.21 \\
.36 \\
8.6 \times 10^{-4} \\
0.0012 \\
.0040 \\
.022 \\
7.2 \\
0.020\end{aligned}$ & $\begin{array}{c}13 \\
3.9 \\
210 \\
\mathrm{~d} 21 \\
0.52 \\
\mathrm{c} .62 \\
.0012 \\
.0031 \\
.067 \\
.052 \\
\mathrm{~d} 19 \\
0.068\end{array}$ & $\begin{aligned} 42 \\
4.1 \\
410 \\
66 \\
9.3 \\
0.31 \\
9.4 \times 10^{-4} \\
0.31 \\
8.1 \\
0.15 \\
85 \\
3.1\end{aligned}$ \\
\hline
\end{tabular}

a Given by Martin and Tech [19] with whom we agree.

b Given by Martin and Corliss [20], who obtained 99, 9.1, respectively.

c Given by Osterbrock [21] with whom we agree.

d Given by Edlén [22] and Osterbrock [21], with whom we agree.

${ }^{\text {e }}{ }^{3} \mathrm{P}_{0} \rightarrow{ }^{3} \mathrm{P}_{1}$ in Se I, Br II and Kr III, ${ }^{3} \mathrm{P}_{1} \rightarrow{ }^{3} \mathrm{P}_{0}$ in Te I, I II, Xe III, and Po I. 
parameters than we use. The writer has given reasons [46] for prefering to treat the term intervals as unconnected by a Slater relation whenever this is feasible (as it is for $p^{n}$ configurations), and accordingly all the atoms have been treated in this way in the present work on $p^{n}$ configurations. Our use of an extra adjustable parameter results in a closer fit of theory and observation. In the only case where earlier work is comparable with ours [43] our results agree closely.

\subsection{Estimation of $\mathbf{s}_{q}$}

The most uncertain part of the calculations is the estimation of the radial integrals $s_{q}$. For GaI, GeI, Asi, Ser, and $\mathrm{Br}$ I (and for Kri and RbIr, which were needed for extrapolation purposes) the selfconsistent field with exchange wave functions of Watson and Freeman [47] were used, and for $\mathrm{Kr}$ I as a check the wave function of Worsley [48]. For other $4 p^{n}$ configurations we assumed that the $\mathrm{Rb}$ II minus Kr I difference in $s_{q}^{-1 / 2}$ (linear in a tomic number) should be added to the values of $s_{q}{ }^{-1 / 2}$ for the neutral atoms to get the values for the corresponding ions, and by repeating the process values were obtained for doubly ionized atoms. Values of $s_{q}$ were collected for many atoms in the $3 p^{n}[49,52]$ and $2 p^{n}[42,50,51]$ configurations. These were used with, the values for $4 p^{n}$ configurations to extrapolate $s_{q}^{-1 / 2}$ to the $5 p^{n}$ and $6 p^{n}$ configurations. In these very rough calculations consideration was given to the variation of the effective quantum numbers derived from the energies and from the values of $s_{q}$ for $2 p^{n}, 3 p^{n}$, and $4 p^{n}$ configurations. Some smoothing was applied to the estimates within the $5 p^{n}$ and $6 p^{n}$ rows of atoms. The finally adopted values of $s_{q}$ are listed in table 26 . The values of $s_{q}$ for the $4 p^{n}$ configurations are thought to be reasonably reliable; the values for the $5 p^{n}$ and $6 p^{n}$ configurations are much less certain.

TABLE 26. Adopted values of $\mathrm{s}_{q}=\frac{2}{5} \overrightarrow{\mathrm{r}^{2}}$ for $\mathrm{p}^{n}$ configurations ${ }^{a}$ ( $s_{\mathrm{q}}$ in atomic units)

\begin{tabular}{|c|c|c|c|c|c|c|}
\hline & & $p$ & $p^{2}$ & $p^{3}$ & $p^{4}$ & $p^{5}$ \\
\hline 4 & $\begin{array}{l}\text { I } \\
\text { III }\end{array}$ & $\begin{array}{l}5.54 \\
3.58 \\
2.51\end{array}$ & 3. 84 & 2. 95 & $\begin{array}{l}\text { 2. } 48 \\
\text { 1. } 9 \\
\text { 1. } 4\end{array}$ & $\begin{array}{l}\text { 2. } 09 \\
\text { 1. } 58 \\
\text { 1. } 24\end{array}$ \\
\hline 5 & $\begin{array}{l}\text { II } \\
\text { III }\end{array}$ & $\begin{array}{l}6.0 \\
4.3 \\
3.2\end{array}$ & 4. 5 & 3. 8 & $\begin{array}{l}3.1 \\
2.4 \\
2.0\end{array}$ & $\begin{array}{l}2.8 \\
2.2 \\
1.8\end{array}$ \\
\hline 6 & $\begin{array}{l}\text { I } \\
\text { II } \\
\text { III }\end{array}$ & $\begin{array}{l}5.3 \\
\text { 4. } 1 \\
\text { 3. } 3\end{array}$ & $\begin{array}{l}\text { 4. } 4 \\
3.5\end{array}$ & 4. 0 & 3.7 & 2. 1 \\
\hline
\end{tabular}

a $4,5,6$ are the principal quantum numbers, I, II, III are spectrum numbers; e.g., $4 p^{5} \mathrm{Kr}$ II has $s_{q}=1.58$. Atomic units used.

\subsection{Accuracy of Results}

The magnetic dipole transition probabilities do not depend on the radial integral $s_{q}$, and they are therefore believed to be quite accurate, probably within 20 percent of the true values. It is very difficult to estimate the accuracy of our adopted values of $s_{q}$ and hence of the electric quadrupole transition probabilities. Jenkins and Mrozowski [33] showed that the line $\mathrm{Pb}$ I $6 p^{2}{ }^{1} \mathrm{D}_{2}-{ }^{3} \mathrm{P}_{1} \quad \lambda 7330$ had 2.2 percent admixture of electric quadrupole radiation. According to our calculations the proportion is 3.3 percent, and 6.9 percent on combining the results of Gerjuoy [18] and Mrozowski [53]. This may suggest that the true $s_{q}$ are rather smaller than the ones we have adopted, the work of Jenkins and Mrozowski being believed to be fairly reliable. The calculated intensity ratios are $I(4618): 1(5313)=$ $9.0: 1$ and $I(4659): I(7330): I(9250)=0.0019: 1: 0.70$, which may be compared with the observed values of Mrozowski [32] of 5.0:1 and $0.023: 1: 0.84$. The discrepancy in $I(4659)$ is not unduly disturbing because this line is rather sensitive to the parameters involved. The other calculated intensities are outside the probable errors given by Mrozowski, and the discrepancies cannot be explained by a reduction in $s_{q}$. Probably there were some undetected errors in the experimental intensities. In Bi I, for $\lambda 6476\left({ }^{2} \mathrm{D}_{5 / 2}{ }^{-4} \mathrm{~S}_{3 / 2}\right)$ the percentage of the total intensity due to electric quadrupole radiation is 20 percent according to our calculations; according to the observations of Mrozowski. [38] the percentage did not exceed 15 percent (upper limit). This discrepancy could be explained if our $s_{q}$ were rather too large. The calculated percentage of electric quadrupole radiation in $\lambda 5640\left({ }^{2} \mathrm{P}_{3 / 2}{ }^{-2} \mathrm{D}_{5 / 2}\right)$ is about 30 percent; it does not exceed 10 percent for the other lines observed by Mrozowski. Our transition probabilities for 'Te I are in agreement with Niewodniczanski and Lipinski's [40] comment (mentioned above) that $\lambda 5420$ is the strongest line from ${ }^{1} \mathrm{~S}_{0}$. No other experimental results appear to be available. A new experimental determination of $s_{q}$ from intensity measurements for one or more ions would be of interest.

\section{5. $d^{9} s^{2}+d^{10} s$ Configurations in $\mathrm{Hg}$ II}

There is one other important group of forbidden lines in a heavy atom, those in $\mathrm{Hg}_{\mathrm{g}} \mathrm{II}$. Déjardin [55] observed the line ${ }^{2} \mathrm{D}_{3 / 2}-{ }^{2} \mathrm{~S}_{1 / 2}(\lambda 1978)$, Paschen [56] observed ${ }^{2} \mathrm{D}_{5 / 2}-{ }^{2} \mathrm{~S}_{1 / 2}(\lambda 2815)$, and Naudé [57] observed ${ }^{2} \mathrm{D}_{3 / 2}-^{2} \mathrm{D}_{5 / 2}(\lambda 6647)$. These transitions occur within the configurations $d^{9} s^{2}+d^{10} s$. Later observations were made by Sambursky [58] and Mrozowski [59]. Mrozowski showed that $\lambda 2815$ is due to electric quadrupole radiation.

The line strengths of the transitions were obtained from the work of Shortley [7] for magnetic dipole radiation and from that of Garstang [16] for electric quadrupole radiation. As usual it is difficult to estimate the radial integrals involved. The results involve the integral

$$
s_{q}(s, d)=\int_{0}^{\infty} r^{2} \mathrm{P}(6 s) \mathrm{P}(5 d) d r
$$


where $\mathrm{P}(6 s)$ is the radial wave function for the $6 s$ electron in the $5 d^{9} 6 s^{2}$ configuration and $\mathrm{P}(5 d)$ that for the $5 d$ electron in the $5 d^{10} 6 s$ configuration. For a heavy atom relativistic wave functions should be used, and then the $d^{10}$ group subdivides into six $d$ electrons and four $\bar{d}$ electrons, and the appropriate one must be used. The integral

$$
s_{q}(d, \bar{d})=\int_{0}^{\infty} r^{2} \mathrm{P}(5 d) \mathrm{P}(5 \bar{d}) d r
$$

is also required for the transition ${ }^{2} \mathrm{D}_{3 / 2}-{ }^{2} \mathrm{D}_{5 / 2}$. Wave functions for $\mathrm{Hg}$ II do not appear to be available, but relativistic self-consistent field wave functions without exchange are available for neutral mercury, and we use the results of Mayers [60] for the $5 d^{10} 6 s^{2}$ configuration. From his wave functions it is found that $s_{q}(s, d)=-4.05, s_{q}(s, \bar{d})=-3.53$, and $s_{q}(d, \bar{d})=+2.87$. Generally speaking the effect of exchange is to reduce the values of $s_{q}$, and increased ionization has the same effect. For the purposes of making rough numerical estimates we have taken for the $5 / 2-1 / 2$ transition $s_{q}(s, d)=-2.7$, for the $3 / 2-1 / 2$ transition $s_{q}(s, \bar{d})=$ -2.4 , and for the $3 / 2-5 / 2$ transition $s_{q}(d, \bar{d})=+2.0$. These values have been used in deriving the transition probabilities listed in table 27 . It must be recognized, however, that these values of $s_{q}$ are only rough estimates. An accurate laboratory measurement of the ratio of $\lambda 1978$ and $\lambda 6647$ would be of exceptional interest.

\section{TABLE 27. Transition probabilities in [Hg II]}

$$
\text { (Units: } \sec ^{-1} \text { ) }
$$

\begin{tabular}{|c|c|c|}
\hline Transition & $A_{m}$ & $A_{q}$ \\
\hline $\begin{array}{ll}5 d^{9} 6 s^{2}{ }^{2} \mathrm{D}_{3 / 2}-5 d^{9} 6 s^{2} & { }^{2} \mathrm{D}_{5 / 2} \\
5 d^{9} 6 s^{2}{ }^{2} \mathrm{D}_{3 / 2}-5 d^{10} 6 s & { }^{2} \mathrm{~S}_{1 / 2} \\
5 d^{9} 6 s^{2}{ }^{2} \mathrm{D}_{5 / 2}-5 d^{10} 6 s & { }^{2} \mathrm{~S}_{1 / 2}\end{array}$ & $\begin{array}{c}54 \\
-----\end{array}$ & $\begin{array}{l}0.029 \\
42 \\
9.5\end{array}$ \\
\hline
\end{tabular}

I am indebted to L. M. Branscomb and K. G. Kessler for enabling me to work at the National Bureau of Standards in 1961, and again in 1962, and for their hospitality. I am indebted to C. W. Allen for encouragement during that part of the work periormed in London. I am indebted to R. E. Watson for supplying me with a copy of his Report No. 12. Thanks are due to M. J. Price for computing assistance during one of his vacations. I am grateful to A. D. Thackeray, J. C. Polanyi, Mrs. C. M. Sitterly, and W. C. Martin for correspondence or discussions.

\section{References}

[1] R. H. Garstang, in Atomic and Molecular Processes, ed. D. R. Bates, ch. 1 (Academic Press, New York and London, 1962).

[2] C. E. Moore, Atomic energy levels, NBS Circ. 46\%, Vol. I (1949); Vol. II (1952); Vol. III (1958).

[3] S. Pasternack, Astrophys. J. 92, 129 (1940).

[4] E. U. Condon and G. H. Shortley The Theory of Atomic Spectra Cambridge University Press, London, England, 1951).
[5] G. Racah, Phys. Rev. 62, 438 (1942).

[6] R. E. Trees, Phys. Rev. 85, 382 (1952).

[7] G. H. Shortley, Phys. Rev. 5\%, 225 (1940).

[8] R. H. Garstang, Proc. Cambridge Phil. Soc. 53, 214 (1957).

[9] R. E. Watson, Tech. Report No. 12, Solid State and Molecular Theory Group, Mass. Inst. Technology, June $15,1959$.

[10] I. S. Bowen, Astrophys. J. 121, 306 (1955).

[11] A. D. Thackeray, Monthly Notices Roy. Astron. Soc. 124, 251 (1962)

[12] R. H. Garstang, Monthly Notices Roy. Astron. Soc. 124, $321(1962)$.

[13] R. H. Garstang, Monthly Notices Roy. Astron. Soc. 118, 234 (1958).

[14] G. Racah, Phys. Rev. 63, 367 (1943).

[15] G. Racah and Y. Shadmi, Bull. Res. Council Israel 8F, 15 (1959).

[16] R. H. Garstang, Proc. Cambridge Phil. Soc. 54, 383 (1958).

[17] A. D. Thackeray, Monthly Notices Roy. Astron. Soc. 113, 211 (1953).

[18] E. Gerjuoy, Phys. Rev. 60, 233 (1941).

[19] W. C. Martin and J. L. Tech, J. Opt. Soc. Am. 51, 591 (1961).

[20] W. C. Martin and C. H. Corliss, J. Res. NBS, 64A (Phys. and Chem.) No. 6443 (1960).

[21] D. E. Osterbrock, Astrophys. J. 114, 469 (1951).

[22] B. Edlén, Phys. Rev. 65, 248 (1944).

[23] F. M. Walters, BS Sci. Pap., 17, 161 (1922).

[24] C. D. Cole, Bull. Am. Phys. Soc. 6, 74 (1961).

[25] F. E. Eshbach and R. A. Fisher, J. Opt. Soc. Am. 44, 868 (1954).

[26] C. C. Kiess and C. H. Corliss, J. Res. NBS 63A (Phys. and Chem.) No. 3, 1 (1959)

[27] G. H. Shortley, L. H. Aller, J. G. Baker, and D. H. Menzel, Astrophys J. 93, 178 (1941).

128] H. Niewodniczanski, Acta Phys. Polonica, 3, 285 (1934).

[29] H. Gieseler and W. Grotrian, Zeit. Physik 34, 374 (1925).

[30] N. K. Sur, Phil. Mag. 2, 633 (1926).

[31] H. Niewodniczanski, Acta Phys. Polonica 2, 375 (1933).

[32] S. Mrozowski, Phys. Rev. 58, 1086 (1940).

[33] F. A. Jenkins and S. Mrozowski, Phys. Rev. 59, 808, 60, 225 (1941).

[34] C. D. Cole and S. Mrozowski, Phys. Rev. 93, 933 (1954).

[35] C. D. Cole, Bull. Am. Phys. Soc. 5, 412 (1960).

[36] M. Hults and S. Mrozowski, Phys. Rev. 86, 587 (1952).

[37] G. R. Toshniwal, Phil. Mag. 4, 774 (1927).

[38] S. Mrozowski, Phys. Rev. 69, 169 (1946).

[39] J. E. Ruedy and R. C. Gibbs, Phys. Rev. 46, 880 (1934).

[40] H. Niewodnicanski and F. Lipinski, Nature, 142, 1160 (1938).

[41] S. Mrozowski, J. Opt. Soc. Am. 46, 663 (1956).

[42] R. H. Garstang, Monthly Notices Roy. Astron. Soc. 111, 115 (1951)

[43] T. M. Helliwell, Astrophys. J. 133, 566 (1961).

[44] J. C. van den Bosch and P. F. A. Klinkenberg, Proc. Ned. Akad. Wetens. 44, 556 (1941).

[45] S. Goudsmit, Phys. Rev. 35, 1325 (1930).

[46] R. H. Garstang, Proc. Cambridge Phil. Soc. 52, 107 (1956).

[47] R. E. Watson and A. J. Freeman, Phys. Rev. 124, 1117 (1961).

[48] B. H. Worsley, Proc. Roy. Soc. A247, 390 (1958).

[49] S. J. Czyzak, Astrophys. J. Supp. \%, 53 (1962).

[50] R. H. Garstang, Astrophys. J. 115, 506 (1952).

[51] B. H. Worsley, Can. J. Phys. 36, 289 (1958).

[52] D. R. Hartree and W. Hartree, Proc. Roy. Soc. A166, 450 (1938)

[53] S. Mrozowski, Reviews Mod. Phys. 16, 153 (1944).

[54] A. H. Joy and P. Swings, Astrophys. J. 102, 353 (1945).

[55] G. Déjardin, Ann. Phys. 8, 424 (1927).

[56] F. Paschen, Ber. Preuss. Akad. Wiss. 32, 536 (1928).

[57] S. M. Naudé, Ann. Physik, 3, 1 (1929).

[58] S. Sambursky, Zeit. Physik $\mathbf{9 6}, 266$ (1932).

[59] S. Mrozowski, Phys. Rev. 57, 207 (1940).

[60] D. F. Mayers, Proc. Roy. Soc. A241, 93 (1957).

[61] A. H. Joy, Astrophys. J. 133, 493 (1961). 


\section{Appendix. Electric Quadrupole Multiplet Strengths for the Transition Arrays $d^{n}-d^{n-1} s$}

In an earlier paper Garstang [16] showed how to calculate electric quadrupole line strengths for many transitions involving $s$ and $d$ electrons. Among these were the transitions $d^{n}-d^{n-1} s$. Detailed results were given for $d^{9}-d^{8} s$ and $d^{7}-d^{6} s$. It was also shown that $S_{q}\left(d^{n} \alpha S L-d^{n-1}\left(\alpha_{1} S_{1} L_{1}\right) s S L_{1}\right)=S_{q}\left(d^{11-n}\right.$ $\left.\alpha_{1} S_{1} L_{1}-d^{10-n}(\alpha S L) s S_{1} L\right)$ so that values for the arrays $d^{11-n}-d^{10-n} s$ can be obtained from those for $d^{n}-d^{n-1} s$. The phases of the matrix elements for the former array are $(-1)^{S+S_{1}+L+L_{1}-1 / 2}$ times those of $d^{n}-d^{n-1} s$; an extra $(-1)$ has to be introduced for $n=6$ if $\alpha_{1} S_{1} L_{1}$ has seniority 3 . Thus the transitions $d^{2}-d s$ and $d^{4}-d^{3} s$ need not be listed. We list here results for $n=1,3$, and 5 . The tabulated quantities are $S_{q}\left(\alpha S L, \alpha^{\prime} S L^{\prime}\right)$, as multiples of $s_{q}^{2}$ where

$$
s_{q}=\int_{0}^{\infty} r^{2} \mathrm{P}(d) \mathrm{P}(s) d r
$$

involves the radial wave functions of the $d$ electron in the $d^{n}$ configuration and the $s$ electron in the $d^{n-1} s$ configuration. As superscript prefixes to the strengths there have been inserted the signs of the square roots of the strengths (i.e., of the matrix elements $\left.\left(\alpha S L\left\|T^{(2)}\right\| \alpha^{\prime} S L^{\prime}\right)\right)$ required in determining the phases for intermediate coupling calculations. Racah's seniority numbers are given as subscripts to the term symbols. The strengths of individual lines may be obtained (in $L S$-coupling: in cases where there is only one term of the same kind as each of the initial and final terms of the desired transition by a direct application of [8, eqs (3), (5), and (6)]. In cases where there are more than one term of the same kind in either or both of the initial and final states, much more elaborate calculations must be performed, as for example for Fe II [12].

TABLE 28. Electric quadrupole multiplet strengths

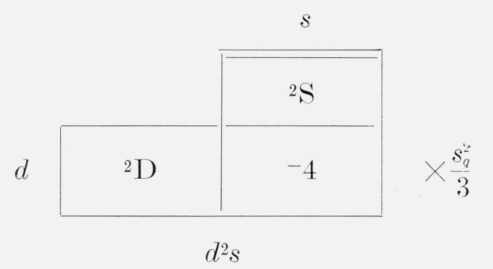

\begin{tabular}{|c|c|c|c|c|c|}
\hline & ${ }^{2} \mathrm{~S}$ & ${ }^{2} \mathrm{P}$ & ${ }^{2} \mathrm{D}$ & ${ }^{2} \mathrm{~F}$ & ${ }^{2} \mathrm{G}$ \\
\hline${ }^{2} \mathrm{P}$ & 0 & -294 & -630 & +336 & 0 \\
\hline${ }_{1}^{2} \mathrm{D}$ & -560 & +315 & +175 & +735 & +315 \\
\hline${ }_{3}^{2} \mathrm{D}$ & 0 & +735 & -675 & -315 & +375 \\
\hline${ }^{2} \mathrm{~F}$ & 0 & -1176 & +420 & -294 & ${ }^{+}+1050$ \\
\hline${ }^{2} \mathrm{G}$ & 0 & 0 & +900 & -1890 & -990 \\
\hline${ }^{2} \mathrm{H}$ & 0 & 0 & 0 & +2310 & -2310 \\
\hline
\end{tabular}

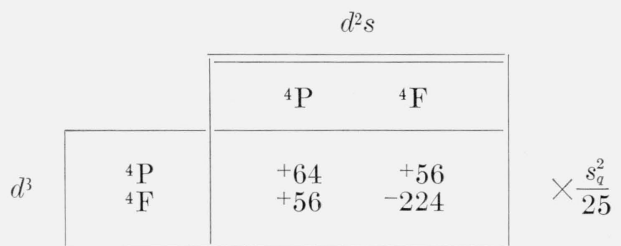


$d^{4} s$

\begin{tabular}{|c|c|c|c|c|c|c|c|c|}
\hline & $\left({ }_{2}^{3} \mathrm{P}\right)^{4} \mathrm{P}$ & $\left({ }_{4}^{3} \mathrm{P}\right)^{4} \mathrm{P}$ & $\left({ }^{3} \mathrm{D}\right){ }^{4} \mathrm{D}$ & $\left({ }^{5} \mathrm{D}\right){ }^{4} \mathrm{D}$ & $\left({ }_{2}^{3} \mathrm{~F}\right)^{4} \mathrm{~F}$ & $\left({ }_{4}^{3} \mathrm{~F}\right)^{4} \mathrm{~F}$ & $\left({ }^{3} \mathrm{G}\right){ }^{4} \mathrm{G}$ & $\left({ }^{3} \mathrm{H}\right){ }^{4} \mathrm{H}$ \\
\hline $\begin{array}{l}{ }^{4} \mathrm{P} \\
{ }^{4} \mathrm{D} \\
{ }^{4} \mathrm{~F} \\
{ }^{4} \mathrm{G}\end{array}$ & $\begin{array}{r}+896 \\
0 \\
+784 \\
0\end{array}$ & $\begin{array}{r}-196 \\
-1260 \\
+224 \\
0\end{array}$ & $\begin{array}{r}-490 \\
+1350 \\
+210 \\
-750\end{array}$ & $\begin{array}{l}+1050 \\
+1750 \\
+2450 \\
+3150\end{array}$ & $\begin{array}{r}+784 \\
0 \\
-3136 \\
0\end{array}$ & $\begin{array}{r}-784 \\
+840 \\
-196 \\
+2100\end{array}$ & $\begin{array}{r}0 \\
-1800 \\
+1260 \\
+1980\end{array}$ & $\begin{array}{r}0 \\
0 \\
+1540 \\
-4620\end{array}$ \\
\hline
\end{tabular}
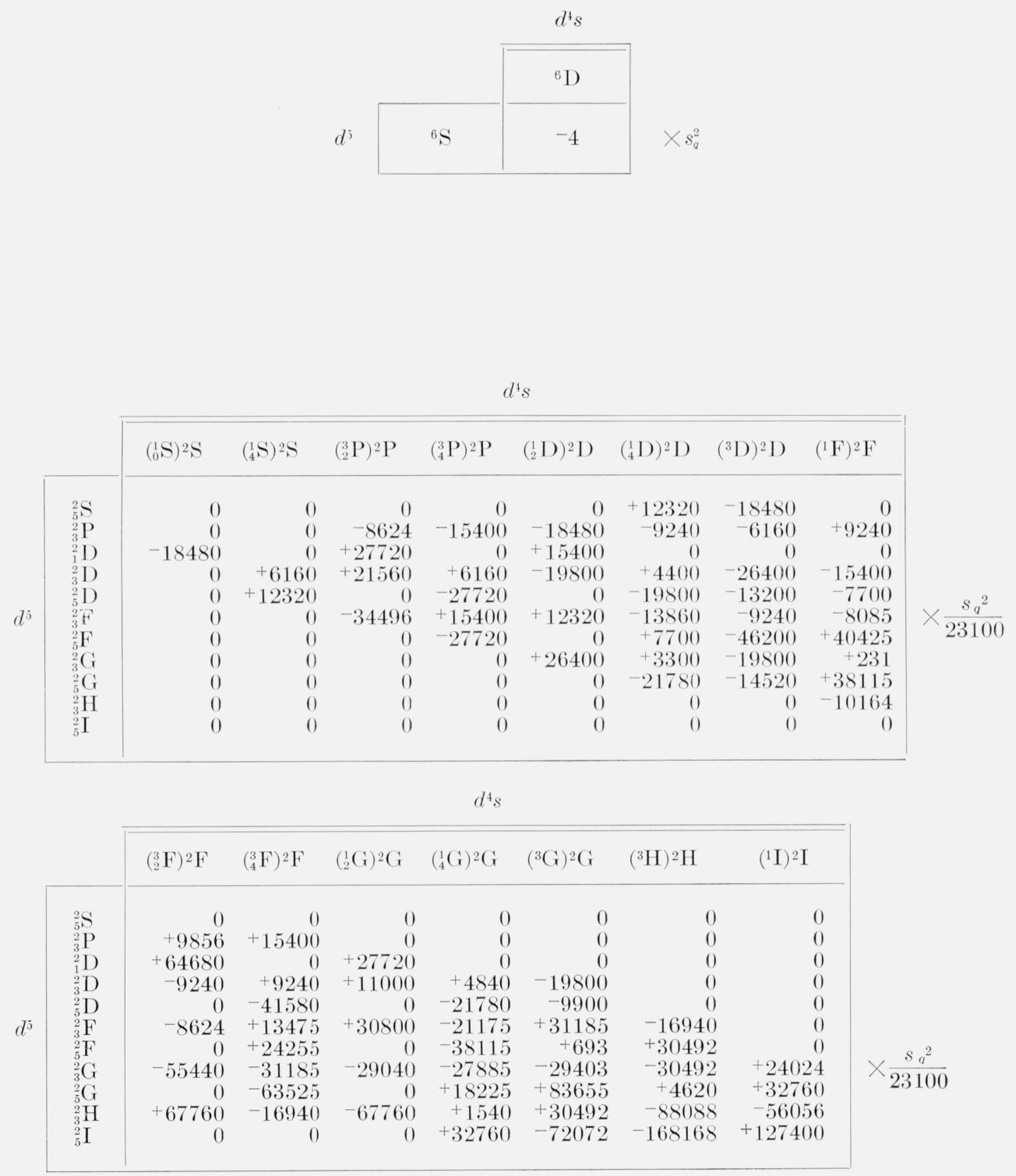

(Paper 68A1-253) 